\title{
Analysis of emission data from global commercial aviation: 2004 and 2006
}

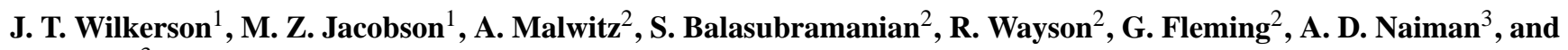 \\ S. K. Lele $^{3}$ \\ ${ }^{1}$ Civil and Environmental Engineering, Stanford University, Stanford CA, USA \\ ${ }^{2}$ Volpe National Transportation Systems Center, US Department of Transportation, Cambridge, MA, USA \\ ${ }^{3}$ Aeronautics and Astronautics, Stanford University, Stanford CA, USA
}

Received: 21 December 2009 - Published in Atmos. Chem. Phys. Discuss.: 5 February 2010

Revised: 16 June 2010 - Accepted: 18 June 2010 - Published: 14 July 2010

\begin{abstract}
The global commercial aircraft fleet in 2006 flew 31.26 million flights, burned 188.20 million metric tons of fuel, and covered 38.68 billion kilometers. This activity emitted substantial amounts of fossil-fuel combustion products within the upper troposphere and lower stratosphere that affect atmospheric composition and climate. The emissions products, such as carbon monoxide, carbon dioxide, oxides of nitrogen, sulfur compounds, and particulate matter, are not emitted uniformly over the Earth, so understanding the temporal and spatial distributions is important for modeling aviation's climate impacts. Global commercial aircraft emission data for 2004 and 2006, provided by the Volpe National Transportation Systems Center, were computed using the Federal Aviation Administration's Aviation Environmental Design Tool (AEDT). Continuous improvement in methodologies, including changes in AEDT's horizontal track methodologies, and an increase in availability of data make some differences between the 2004 and 2006 inventories incomparable. Furthermore, the 2004 inventory contained a significant over-count due to an imperfect data merge and daylight savings error. As a result, the 2006 emissions inventory is considered more representative of actual flight activity. Here, we analyze both 2004 and 2006 emissions, focusing on the latter, and provide corrected totals for 2004. Analysis of 2006 flight data shows that $92.5 \%$ of fuel was burned in the Northern Hemisphere, $69.0 \%$ between $30 \mathrm{~N}$ and $60 \mathrm{~N}$ latitudes, and $74.6 \%$ was burned above $7 \mathrm{~km}$. This activity led to $162.25 \mathrm{Tg}$ of carbon from $\mathrm{CO}_{2}$ emitted glob-
\end{abstract}

Correspondence to: J. T. Wilkerson (wilkejt1@stanford.edu) ally in 2006, more than half over three regions: the United States (25.5\%), Europe (14.6), and East Asia (11.1). Despite receiving less than one percent of global emissions, the Arctic receives a uniformly dispersed concentration of emissions with $95.2 \%$ released at altitude where they have longer residence time than surface emissions. Finally, $85.2 \%$ of all flights by number in 2006 were short-haul missions, yet those flights were responsible for only $39.7 \%$ of total carbon from $\mathrm{CO}_{2}$. The following is a summary of these data which illustrates the global and regional aviation emissions footprints for 2004 and 2006, and provides temporal and spatial distribution statistics.

\section{Introduction}

This study provides an analysis of aviation emissions data for global commercial aircraft flights in 2004 and 2006. Previous aircraft emissions inventories have shown that most activity occurs in the Northern Hemisphere mid-latitudes (Baughcum et al., 1996a, b; Sutkus Jr. et al., 2001; Eyers et al., 2005; Kim et al., 2005c, 2007). Simply scaling data from earlier studies by projected global industry growth rate of 5-7\% per annum (ICAO, 2007) may not provide emission trends that are representative of geographically varying growth in the aviation sector. For example, India reported an increase in its domestic aviation activity by $41 \%$ from 2005 to 2006 (MOCA, 2007). As such, it is necessary to update and analyze aircraft emission inventories for use in atmospheric models and policy studies.

Published by Copernicus Publications on behalf of the European Geosciences Union. 
Data for this analysis were provided by the Volpe National Transportation Systems Center. Here, we provide a brief review of the processes and methods used by Volpe to assemble the data and provide emission summary statistics for carbon dioxide $\left(\mathrm{CO}_{2}\right)$, nitrogen oxides $\left(\mathrm{NO}_{\mathrm{x}}\right)$, sulfur compounds $\left(\mathrm{SO}_{\mathrm{x}}\right)$, speciated organic gases, and speciated particle components (black carbon, primary organic matter, and sulfate) from commercial aircraft. We also analyze the vertical profile of emissions, particularly in the upper troposphere and lower stratosphere (UTLS) and emissions in major regions of the world. We then examine the emissions over the Arctic, since it is a particularly sensitive region to climate change. Finally, we compare results with those from previous datasets. We do not examine general aviation or military aircraft emissions because such emissions are generally not reported or reported separately and not provided. It has been estimated that the military contribution is in the range of $10-13 \%$ of total emissions (Eyers et al., 2005; Waitz et al., 2005).

Aviation emission inventories are important inputs into atmospheric models examining the climate and pollution effects of aircraft and other anthropogenic emission sources. For example, both inventories discussed here are currently being used in companion studies to examine the effects of aircraft on global climate, atmospheric composition, contrails, and contrail-induced cirrus by treating each aircraft flight at the subgrid scale (Jacobson et al., 2010). It would not be possible to study the effects of subgrid-scale aircraft exhaust plumes and contrails in a global model with an inventory that did not separate emissions by individual flights broken into spatial and temporal segments. Due to the large volume of data in such an inventory, it is important to evaluate and summarize the data in a meaningful way. We attempt to do this in the following sections.

This paper presents emissions inventories from two years, 2004 and 2006, along with additional statistics for a corrected 2004 inventory. Differences between the original 2004 inventory and the 2006 inventory, due to changes in Volpe's methodology, availability of radar data, emissions Indices (EI), and other factors, are discussed herein. Because of these differences, comparisons between the original 2004 and 2006 data are limited to global methodology comparisons, and those data sets should not be compared directly with each other to show spatial trends between the two years. However, corrected 2004 global emission totals based on the 2006 methodology, are presented. These numbers do allow a comparison of global trends between 2004 and 2006. The 2006 dataset is considered the benchmark inventory. Below, we address the 2006 data set and both the original and corrected 2004 inventories.

\section{Methodology}

\subsection{Global inventory source and description}

The United States (US) Federal Aviation Administration (FAA), with support from Volpe, developed the Aviation Environmental Design Tool (AEDT) (Roof et al., 2007). The emission module of AEDT, the System for assessing Aviation's Global Emissions (SAGE), was developed to provide a method for evaluating the effects of various policy, technology, and operational scenarios on aircraft fuel use and emissions. The tool predicts aircraft fuel burn and emissions for all global commercial flights at high temporal resolution (seconds to minutes) over each year, enabling single-flight analysis scenarios, and airport, country, regional, and global scenarios. The module dynamically models aircraft performance, fuel burn and emissions, capacity and delays at airports, and is also capable of providing forecast scenarios. The process for obtaining the flight-level emissions is briefly summarized below but is described in much greater detail in several publications (Kim et al., 2005a, b, c, 2007; Lee et al., 2005, 2007; Malwitz et al., 2005).

The AEDT inventory provides four-dimensional (latitude, longitude, altitude, and time) flight trajectories using as much real data as possible as described below. The data are collected by the Enhanced Traffic Management System (ETMS) at the Volpe Center, which serves as the hub of information. ETMS receives a continuous flow of data from numerous sources, including Terminal Radar Approach Control Facilities (TRACON), individual airlines, Automated Radar Tracking Systems (ARTS), and Air Route Traffic Control Centers (ARTCC). ETMS is the FAA's electronic recording of flight position and flight plan information used for air traffic management. It captures every flight within coverage of FAA radars, including scheduled, cargo, military (later excluded), charter, and unscheduled flights. Unscheduled flights have been estimated to account for as much as $9 \%$ of flights globally; in the non-radar portions of AEDT data unscheduled flights are included by scaling known flights (Kim et al., 2005b). ETMS also captures information about every flight that files a flight plan, whether or not the aircraft enters radar-controlled airspace. Radar coverage encompasses all of North America and parts of Western Europe, and records an estimated 50-60\% of global commercial flights (Volpe, 2003). Additionally, in the 2006 inventory, data collected by EUROCONTROL's Enhanced Tactical Flow Management System (ETFMS) were included. This expanded AEDT's total radar-provided schedule and flight data to include most of Europe. For the 2004 inventory data, European operations were represented primarily by the Official Airline Guide (OAG), where ETMS coverage did not exist (e.g., in Europe).

When radar tracking is unavailable or information is incomplete for a particular flight, the tool refers to the OAG, which lists scheduled passenger flights by participating 
airlines. The guide represents all US scheduled airlines and the majority of scheduled worldwide airlines. For incomplete ETMS flights and all of ETFMS and OAG flights, trajectories are generated. In 2004, trajectories were generated from statistical distributions of cruise altitudes and horizontal tracks between origination and destination (OD) airport pairs. The distributions for a given flight-distance category (e.g., 200$250 \mathrm{~nm}$ ) were generated at Volpe by statistically analyzing a large set of ETMS flights for jet or turboprop engines, the percentage of each flight that occurred along the OD Great Circle (GC), the distance from the GC, and the probability of the offset distance from the GC. The resulting distributions of horizontal tracks provide a "dispersion" effect around the OD GC estimate. An analogous method was applied to determine cruise altitudes.

For 2006, the same method was used to determine cruise altitude, but a more accurate flight corridor matching or "airways track" method was used which better represents nonradar flight trajectories by learning where scheduled flights usually fly when travelling between a given OD pair. This method determines the shortest distance for flights traveling between common OD pairs as the horizontal track, which better reflects where these aircraft typically fly. If a valid airways track did not exist between an OD pair (e.g. when track data between the two airports is non-existent), then a dispersed GC track was used as in the 2004 data. The airways track approach closely resembles radar data when comparing both within AEDT, neglecting reroutes due to adverse weather.

This AEDT emissions inventory is similar to the European AERO2k database (Eyers et al., 2005). Where AEDT uses ETMS, ETFMS if available, and OAG data as the main components; AERO2k supplements actual flight data with schedule data from the Back Aviation database (fleet registration), and by airspace route structure information (Michot et al., 2004). The agencies that control these databases, FAA and EUROCONTROL, have increased the amount of exchange of flight-movement information; so, both databases are expected to improve in accuracy and completeness as collaboration continues.

Once flight trajectories are identified within AEDT and SAGE, each flight is divided into multiple linear segments, or chords. Each chord includes spatial and temporal information of the chord, flight identification information, and pertinent performance parameters such as aircraft and engine type. The horizontal and vertical resolution of the segment end points are $10^{-6}$ degrees and $10^{-4} \mathrm{~m}$ respectively, and the time is resolved to integer seconds. Each flight may consist of a few dozen to several hundred chords, and the length of each chord is determined by dynamic parameters such as significant change in aircraft speed or altitude, or in horizontal deviation.

\subsection{Fuel burn and emissions}

After creation of the movement database described above, AEDT calculates chord-level fuel burn and emissions. This requires knowledge of takeoff weights, aircraft performance data, and emission data. Validation assessments have shown that SAGE can predict fuel burn to within 3\% of airline data (Kim et al., 2007). The emission module then generates estimates of emissions based on the amount of fuel burned and on emission indices for each species (Table 1). Values reported here fall within the ranges summarized by the ATTICA team (Lee et al., 2010). Emissions of $\mathrm{CO}_{2}$, water vapor $\left(\mathrm{H}_{2} \mathrm{O}\right.$ ), and $\mathrm{SO}_{\mathrm{x}}$ (modeled as $\left.\mathrm{SO}_{2}\right)$ follow the fuel burn since they are based strictly on total fuel composition using Boeing-derived EI (Hadaller and Momenthy, 1993). Emissions of carbon monoxide (CO), hydrocarbons (HC), and $\mathrm{NO}_{\mathrm{x}}$ are a function of the individual segment performance (e.g. take-off, cruise, etc) so cannot be linearly scaled by total emissions; these species are modeled using Boeing Fuel Flow Method 2 (BFFM2) (Baughcum, 1996b; DuBois and Paynter, 2006).

Changes in $\mathrm{CO}$ and HC EIs, are a result of improvements made in AEDT for terminal-area fuel burn calculations and changes in EIs. The highest EI of CO is at low thrust setting, such as during the idle (taxiing operations) or descent portions of flight. While the terminal area represents a proportionately small amount of the overall fuel burn, it represents a substantial portion of the overall $\mathrm{CO}$ produced.

The EI for black carbon (BC) particulate matter (PM) used in the AEDT's 2004 inventory was $0.2 \mathrm{~g} / \mathrm{kg}$-fuel which represents the EI for PM during a portion of the aircraft operation, including takeoff and climb out; however this represented a small portion of the activity and effectively overpredicts BC emissions. For the 2006 inventory, AEDT chose to use $0.035 \mathrm{~g} / \mathrm{kg}$ for BC EI which is more consistent with cruise emissions. Both 2004 and 2006 EI values fall between the low and high range of other inventories as summarized by Lee et al. (2010). Recent work by Volpe and the FAA (Wayson et al., 2009) has advanced the methodology to estimate PM emissions by disaggregating non-volatile PM from fuel organics and sulfur-related compounds; however, this is intended for airport operations at ground level conditions rather than cruise-related operations. The methodology may be applicable at cruise conditions with modifications; however, this has not been verified.

The PM and gaseous EI predicted by AEDT are continually improved by analysis of aircraft emissions tests which help characterize exhaust plumes as a function of performance such as during taxi, takeoff, cruise and approach. One such study by The Airport Cooperative Research Program summarized emissions by engine type, thrust, and performance, atmospheric conditions, and plume age (Whitefield et al., 2008). However, like most studies of this nature, this is a ground-based experiment. There have also been several 
Table 1. Emissions indices.

\begin{tabular}{|c|c|c|}
\hline Emission Factors & 2004 & 2006 \\
\hline $\mathrm{H}_{2} \mathrm{O}$ emissions ( $\mathrm{g} / \mathrm{kg}$-fuel) & 1237 & 1237 \\
\hline $\mathrm{CO}_{2}-\mathrm{C}$ emissions ${ }^{1}$ (g-C/kg-fuel) & 861 & 862 \\
\hline $\mathrm{NO}_{2}$ emissions ${ }^{2}$ (g/kg-fuel) & $14.5^{5}$ & $14.1^{5}$ \\
\hline $\mathrm{CO}$ emissions (g/kg-fuel) & $2.57^{5}$ & $3.61^{5}$ \\
\hline $\mathrm{SO}_{\mathrm{X}}-\mathrm{S}$ emissions ${ }^{3}$ (g-S/kg-fuel) & 0.578 & 0.588 \\
\hline $\mathrm{HC}\left(\right.$ as $\left.\mathrm{CH}_{4}\right)$ emissions (g/kg-fuel) & $0.350^{5}$ & $0.520^{5}$ \\
\hline Organic PM emissions ${ }^{4}$ (g-POM/kg fuel) & 0.015 & 0.015 \\
\hline Sulfur PM emissions ${ }^{3}$ (g S(VI)-S/kg-fuel) & 0.022 & 0.012 \\
\hline Black Carbon PM emissions (g-BC/kg-fuel) & 0.200 & 0.035 \\
\hline
\end{tabular}

${ }^{1}$ Reported as $3155 \mathrm{~g} \mathrm{CO}_{2} / \mathrm{kg}$ fuel for 2004 , and $3159 \mathrm{~g} \mathrm{CO}_{2} / \mathrm{kg}$ fuel in 2006. Carbon from $\mathrm{CO}_{2}$ obtained by molecular weight ratio: $M_{\mathrm{C}} / M_{\mathrm{CO}_{2}}$

${ }^{2} \mathrm{NO}_{\mathrm{x}}$ converted to $\mathrm{NO}_{2}$ in database;

3 in $2004,96.3 \%$ of the $\mathrm{SO}_{\mathrm{x}}-\mathrm{S}$ was partitioned to $\mathrm{SO}_{2}-\mathrm{S}$ (gas) and $3.7 \%$ to $\mathrm{S}(\mathrm{VI})-\mathrm{S}$ (particle). For 2006, $98 \%$ was partitioned to $\mathrm{SO}_{2}$ $\mathrm{S}$

4 primary organic matter;

5 effective EI based on total emissions and fuel burn. Actual EI is a function of flight activity, such as take-off and cruise, so not constant.

flight-level experiments and results from such studies are added into AEDT's methods when appropriate.

\subsection{Vector to grid conversion}

We analyzed 4-D inventories for 2004 and 2006, which were produced by Volpe using the above methodology. The parameters we used included the beginning and end time, latitude, longitude, and altitude of each flight segment of every flight and the fuel use and emissions of each species during the segment. Emission data were prepared by Volpe into 366 and 365 daily files for 2004 and 2006, respectively, where flight segments, or vectors, were assigned to a specific daily file corresponding to the day of the begin-time of the flight. Each annual dataset contains nearly a Terabyte of flight data in this vector format.

The segment data is appropriate for incorporating the emission data in a climate model that treats subgrid emission plumes and contrails and their spreading due to shear and dilution (Jacobson et al., 2010; Naiman et al., 2010); however, the large daily files are too large and cumbersome to load into computer memory. Consequently, these daily files were further divided into hourly files, which are more manageable and of the same time-scale order as in the numerical climate study. Flight segments were broken into sub-segments and stored in the appropriate hourly file in which each fraction occurred. This resulted in 8784 hourly files for 2004 and 8760 files for 2006. Each hourly file consists of between 200 and 600 thousand segments depending on daily flight activity.

Visualizing the flight emissions data enables a better understanding of spatial and temporal characteristics of the emissions, and a gridded format, rather than vector format, is better suited for this visualization. While Volpe could have provided gridded results at $1^{\circ} \times 1^{\circ} \times 1 \mathrm{~km}$ resolution, gridding the provided vector format allowed for both the visual verification of the vector data and a finer grid resolution than readily available from Volpe. For this study, the individual flight data were converted to $0.5^{\circ} \times 0.5^{\circ} \times 0.5 \mathrm{~km}$ spatial gridded data.

Gridding the data required identifying which altitude and horizontal bins the segment intersected and applying the appropriate fraction of emissions to each bin. This was accomplished with a three-dimensional parametric vector-plane intercept solution. The distance to the vector intersection with the next longitude, latitude, or altitude plane, based on the chosen resolution, determined the fractional amount of the segment emissions applied to each cell. The solution to each gridded segment was then added to the accumulating global gridded dataset. Once all hourly 3-D gridded arrays were written, the individual hourly files were interrogated for statistics such as emissions during a season, over a particular region or above a given altitude.

\subsection{Regional disaggregation}

Gridding the data to the desired resolution facilitates a visual inspection of the data both spatially and temporally, and this global footprint illustrates where the emissions generally occur. However, understanding local emissions enables insight into the regional impacts. The global grid was parsed into regions, and the following describes the two methods used for isolating portions of the global grid.

One method of aggregating emissions into world regions uses the 19 IPCC regions defined in the IMAGE model (RIVA, 2001) which isolates regions on a $1^{\circ} \times 1^{\circ}$ grid resolution. They are identified in Table 2 and illustrated in Fig. 1a. The one-degree resolution was lower than that of the gridded emission data, but allowed for sufficient disaggregation of emissions into logical regions of irregular shapes that roughly match country or region boundaries.

The second method was to isolate major regions of interest with rectangular bounding boxes. These regions were chosen based on peak aviation activity or research interest, such as over the US or the North Atlantic Flight Corridor. These regions are illustrated in Fig. $1 \mathrm{~b}$ and defined in Table 3.

\section{Results}

\subsection{Annual statistics}

Annual totals for the fuel burned, distance travelled, and computed emissions constituents are summarized in Table 4. 
Table 2. IPCC regions (see Fig. 1a for graphical presentation).

\begin{tabular}{llrr}
\hline & IPCC Region & $\begin{array}{r}\text { Total Area } \\
\left(10^{3} \text { sqkm }\right)\end{array}$ & \\
\hline 0 & OCEAN & 327501 & $64.21 \%$ \\
1 & CANADA & 12642 & $2.48 \%$ \\
2 & USA & 11573 & $2.27 \%$ \\
3 & CENTRAL AMERICA & 5354 & $1.05 \%$ \\
4 & SOUTH AMERICA & 20307 & $3.98 \%$ \\
5 & NORTHERN AFRICA & 6591 & $1.29 \%$ \\
6 & WESTERN AFRICA & 12203 & $2.39 \%$ \\
7 & EASTERN AFRICA & 6985 & $1.37 \%$ \\
8 & SOUTHERN AFRICA & 7776 & $1.52 \%$ \\
9 & OECD EUROPE & 6421 & $1.26 \%$ \\
10 & EASTERN EUROPE & 1246 & $0.24 \%$ \\
11 & FORMER USSR & 25157 & $4.93 \%$ \\
12 & MIDDLE EAST & 7110 & $1.39 \%$ \\
13 & SOUTH ASIA & 6068 & $1.19 \%$ \\
14 & EAST ASIA & 12040 & $2.36 \%$ \\
15 & SOUTHEAST ASIA & 9576 & $1.88 \%$ \\
16 & OCEANIA & 13062 & $2.56 \%$ \\
17 & JAPAN & 948 & $0.19 \%$ \\
18 & GREENLAND & 2715 & $0.53 \%$ \\
19 & ANTARCTICA & 14790 & $2.90 \%$ \\
& Total & 510064 & $100.00 \%$ \\
\hline
\end{tabular}

The reported data in the table suggest fuel burn and subsequent emissions decreased between 2004 and 2006; however this is misleading, as the original 2004 data require correction. Corrected 2004 data are also shown in Table 4; however, explanations and a description of corrections for this discrepancy are addressed below, respectively, after a brief description of the results. Other reliable gauges of aviation activity suggest an increase between 2004 and 2006 (OAG, 2007; IEA, 2009), a result similar to that found here once the 2004 data are corrected.

\subsubsection{Global footprint}

In 2006, the global aviation fleet burned 188.20 Tg (or metric tons) of fuel. Figure 2 illustrates where fuel was consumed annually during 2004 and 2006. Several striking features of the emissions distributions are evident from the figures. Nearly all aviation activity occurred in the Northern Hemisphere where $92.5 \%$ of the fuel was consumed in 2006, and $69.0 \%$ of the activity occurred in the Northern mid-latitudes of $30-60^{\circ} \mathrm{N}$. The 2006 inventory was created using an updated version of the AEDT system relative to 2004; thus, there are some visual differences between the original 2004 and the 2006 data in the local distribution of the flight trajectories; especially over Central Asia. As described earlier,
Table 3. Bounds for regional studies (see Fig. 1b for graphical presentation).

\begin{tabular}{llrr}
\hline & Box Region $^{\mathrm{a}}$ & $\begin{array}{r}\text { Total Area } \\
\left(10^{3} \mathrm{sqkm}\right)\end{array}$ & $\%$ Total $^{\mathrm{b}}$ \\
\hline A & United States & 15687 & $3.08 \%$ \\
B & Eastern US & 7711 & $1.51 \%$ \\
C & Western US & 7976 & $1.56 \%$ \\
D & Arctic Region & 21152 & $4.15 \%$ \\
E & Europe & 6630 & $1.30 \%$ \\
F & Eastern Asia & 16126 & $3.16 \%$ \\
G & North Atlantic Flight Corridor & 11430 & $2.24 \%$ \\
H & North Pacific Flight Corridor & 23571 & $4.62 \%$ \\
\hline
\end{tabular}

a Box Region Dimensions:

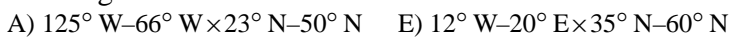

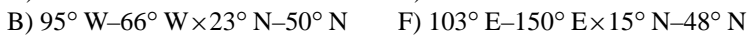

C) $125^{\circ} \mathrm{W}-95^{\circ} \mathrm{W} \times 23^{\circ} \mathrm{N}-50^{\circ} \mathrm{N} \quad$ G) $70^{\circ} \mathrm{W}-5^{\circ} \mathrm{W} \times 40^{\circ} \mathrm{N}-63^{\circ} \mathrm{N}$

D) North of $66.5^{\circ} \mathrm{N}$

H) $140^{\circ} \mathrm{E}-120^{\circ} \mathrm{W} \times 35^{\circ} \mathrm{N}-65^{\circ} \mathrm{N}$

${ }^{\mathrm{b}}$ Column does not sum to $100 \%$

when ETMS radar flight data were not available or incomplete, the 2004 inventory employed a dispersion along the great circle to populate the horizontal tracks, while the 2006 inventory employed a combination of airways track resorting to a dispersed great circle only when an airways track was not available. Both datasets included about the same percentage of non-radar tracks (about 50\%) which occur mostly over Eastern Europe and Asia. Both horizontal track methods attempt to capture the true length of flights. The GC dispersion method estimates flight distances on average, while the airways track method estimates the length of every flight. However, the airways method provides shorter distances overall when compared to the GC dispersion method. While a global comparison of the difference between methods is not available, the latter has been determined by Volpe to be more accurate, suggesting the earlier method over-predicts distances and subsequent fuel burn and emissions.

Recent studies have shown that actual flight paths can increase flight distances an average of $10 \%$ in Europe and 6-8\% in the US compared with direct GC estimated distances (Kettunen et al., 2005). Both horizontal track methods employed by AEDT were aimed at defeating this underprediction by not using a direct GC track for non-radar flights. Kettunen further found that $70 \%$ of the underestimation occurred within the terminal control areas (TCA) which is the volume of space immediately surrounding airports where planes are taking off and landing. So it is possible that neither the 2004 nor the 2006 inventory captured this TCA spatial uncertainty for non-radar flights.

Table 4 also shows several computed global emission constituents. Some species are proportional to fuel burn, including $\mathrm{CO}_{2}$, water vapor, and $\mathrm{SO}_{\mathrm{x}}$. Others, such as $\mathrm{NO}_{\mathrm{x}}$, sulfur, and fuel PM, are performance-based. Due to the 

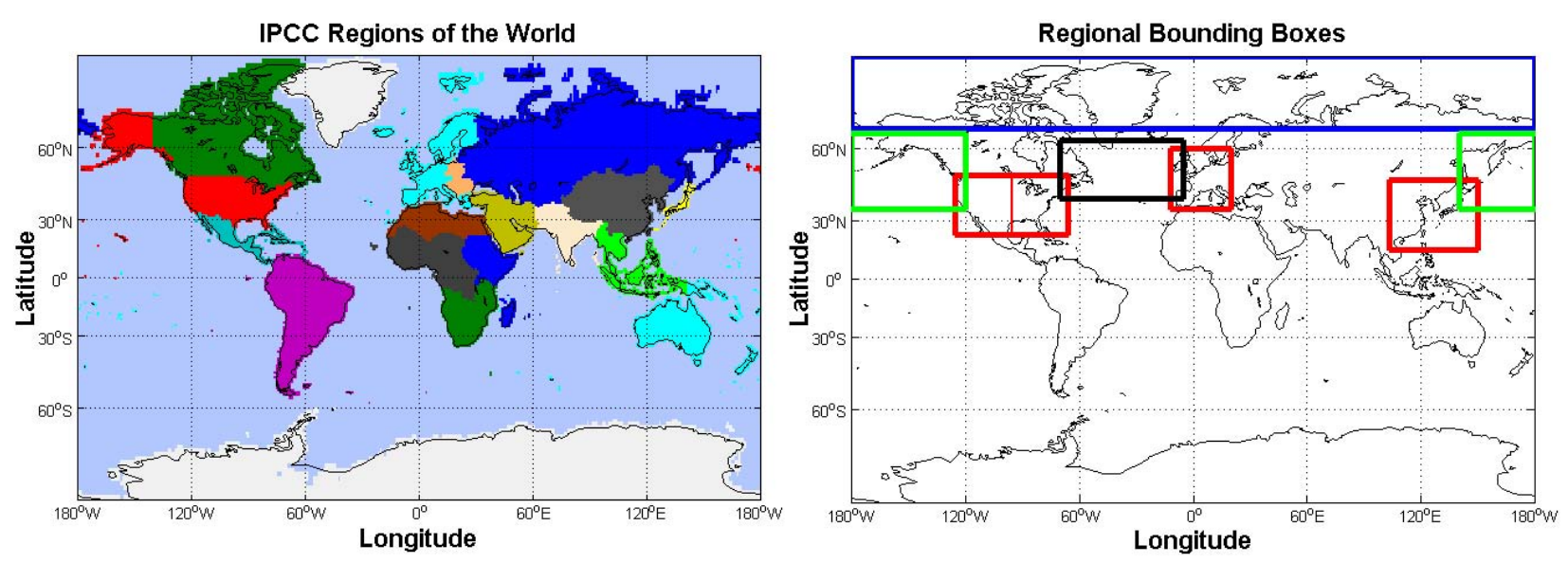

Fig. 1. Regions of the world defined by one of two methods: (a) IPCC Regions based on the IMAGE model (RIVA); (b) Bounding Box Regions identifying regions of principal activity, including the US, Europe, East Asia, Arctic, and North Atlantic and North Pacific Flight Corridors.
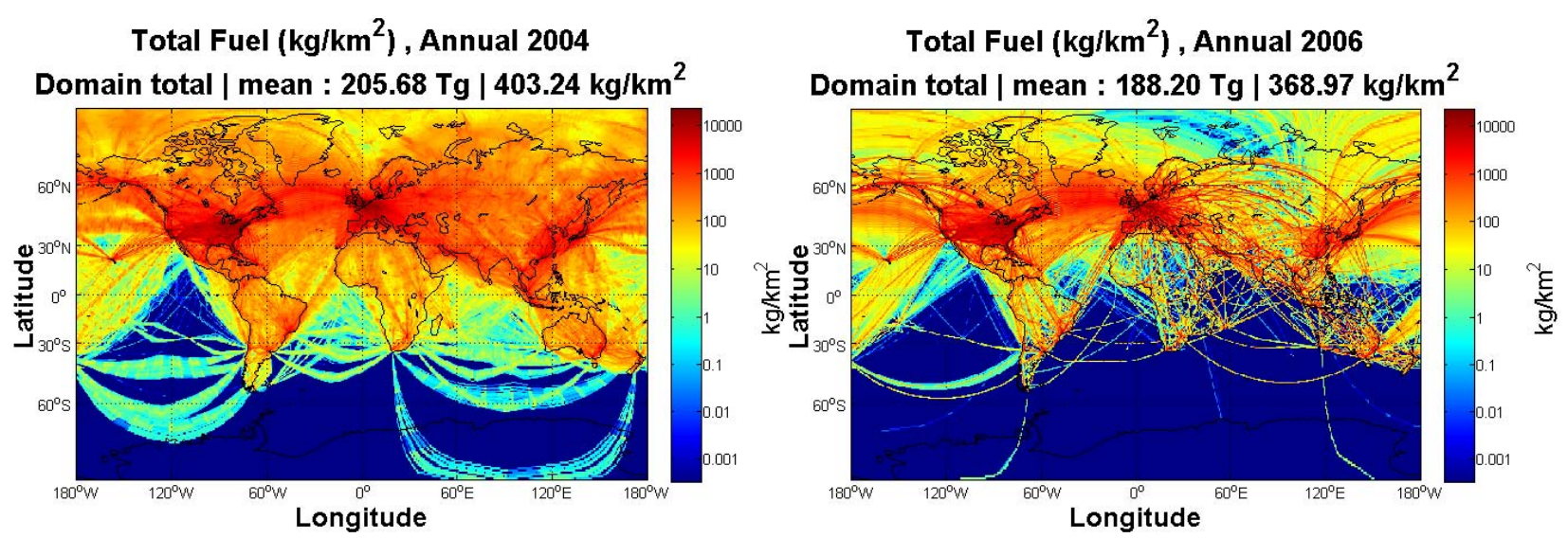

Fig. 2. Spatial distribution of fuel burned in (a) 2004 (uncorrected) and (b) 2006. Global distributions are similar between the two years: nearly all of the emissions occurred in the Northern Hemisphere and about three out of every four grams of fuel was burned in the northern mid-latitudes. Visual differences between the two plots are largely an artifact of the different horizontal track estimation methods used between the two years. The "airways track" method used in 2006 is considered a more accurate representation of actual flight tracks.

previously-mentioned database differences, a quantitative comparison of the reported global totals between uncorrected 2004 and 2006 is not appropriate. However, some differences are significant, such as with $\mathrm{CO}$ and $\mathrm{BC}$, whose emissions changed significantly between 2004 and 2006 despite the corrections discussed shortly. BC decreased significantly due to the use of a more appropriate mean-EI as described in Sect. 2.2. Future improvements of AEDT's model are expected to include performance-based $\mathrm{EI}$ for $\mathrm{BC}$ as well to more accurately compute $\mathrm{BC}$ emissions. Changes in $\mathrm{CO}$, and $\mathrm{HC}$, are a result of improvements made in AEDT for terminal-area fuel burn calculations and changes in EIs. For all species, the 2006 result is considered the benchmark for EI and total results.

\subsubsection{Correction of 2004 data}

Other publications of aviation emission data suggest fuel burn increased between 2004 and 2006. For example: the International Energy Agency (IEA) reported an increase in total primary energy supply of global aviation bunkers from 124.2 Tg in 2004 to $135.0 \mathrm{Tg}$ in 2006 with similar increases in computed $\mathrm{CO}_{2}$ emissions (IEA, 2009). IEA relies on reported information, which may explain why the agency's numbers are lower than in the current study. Also the OAG reported continuous year-over-year growth in the number of seats sold of 3-5\% every year from 2000-2006 (OAG, 2007).

The 2004 fuel burn results reported here are also 8.6\% higher than fuel burn reported for the same year in a previous SAGE inventory report (Kim et al., 2005c), which are shown in Table 5 in units consistent with this study. The 
Table 4. Total annual emissions from global commercial aviation, 2004 and 2006.

\begin{tabular}{|c|c|c|c|c|}
\hline & \multicolumn{2}{|c|}{2004} & \multirow[t]{2}{*}{2006} & \multirow[b]{2}{*}{ (Comments) } \\
\hline & Reported & Corrected $^{\mathrm{e}}$ & & \\
\hline Distance traveled (Billion km) & 41.42 & & 38.68 & \\
\hline Total number of flights (Million) & 33.13 & & 31.26 & \\
\hline Fuel burned $(\mathrm{Tg})$ & 205.68 & 174.06 & 188.20 & \\
\hline In Northern Hemisphere & $92.7 \%$ & & $92.5 \%$ & (\% of Fuel burned) \\
\hline In Northern Mid-Latitudes & $68.9 \%$ & & $69.0 \%$ & $\left(30^{\circ} \mathrm{N}-60^{\circ} \mathrm{N}\right)$ \\
\hline $\mathrm{H}_{2} \mathrm{O}$ emissions $(\mathrm{Tg})$ & 254.42 & 215.31 & 232.80 & \\
\hline $\mathrm{CO}_{2}-\mathrm{C}$ emissions ${ }^{\mathrm{a}}(\mathrm{Tg})$ & 177.09 & 150.06 & 162.25 & $\left(\mathrm{C}\right.$ from $\left.\mathrm{CO}_{2}\right)$ \\
\hline $\mathrm{NO}_{2}$ emissions ${ }^{\mathrm{b}}(\mathrm{Tg})$ & 2.987 & 2.456 & 2.656 & $\left(\mathrm{NO}_{\mathrm{x}}\right.$ as $\left.\mathrm{NO}_{2}\right)$ \\
\hline CO emissions (Tg) & 0.529 & 0.628 & 0.679 & \\
\hline $\mathrm{SO}_{\mathrm{X}}-\mathrm{S}$ emissions ${ }^{\mathrm{c}}(\mathrm{Tg})$ & 0.119 & 0.102 & 0.111 & $\left(\mathrm{~S}\right.$ from $\left.\mathrm{SO}_{\mathrm{x}}\right)$ \\
\hline $\mathrm{HC}\left(\right.$ as $\left.\mathrm{CH}_{4}\right)$ emissions $(\mathrm{Tg})$ & 0.072 & 0.090 & 0.098 & \\
\hline Organic PM emissions (Tg) & 0.1516 & 0.0026 & $0.0030^{\mathrm{d}}$ & \\
\hline Sulfur PM emissions ( $\mathrm{Tg}$ ) & 0.0046 & 0.0021 & 0.0023 & \\
\hline Black Carbon PM emissions (Tg) & 0.0386 & 0.0061 & 0.0068 & \\
\hline
\end{tabular}

a Carbon from $\mathrm{CO}_{2}$ obtained by molecular weight ratio: $M_{\mathrm{C}} / M_{\mathrm{CO}_{2}}$;

b $\mathrm{NO}_{\mathrm{x}}$ Converted to $\mathrm{NO}_{2}$ in database;

c sulfur from $\mathrm{SO}_{\mathrm{x}}$ obtained by molecular weight ratio: $M_{\mathrm{S}} / M_{\mathrm{SO}_{2}}$;

d original 2006 inventory included 0.135 Tg organic PM, modified here to be consistent with BC emissions;

e corrected global fuel burn results for 2004 without over-count but with 2006-equivalent trackways generation. Corrected emissions calculations rely strictly new preliminary fuel burn and 2006 EI values from Table 1.

difference between the two 2004 reports is in small part due to better representation of unscheduled flights in the current report. However, it is largely due to an over-count which is best explained in Sect. 3.2 below. With the recent discovery of this significant over-count (only in the 2004 inventory), Volpe has reprocessed the 2004 emissions. AEDT's capabilities are continually updated, so the new 2004 inventory has been processed very much like the 2006 inventory by using the airways track method for non-radar flights. As such, the corrected 2004 global results in Table 4 are directly comparable with the 2006 global results for trends in aviation activity.

Corrected results provided by Volpe show the total global fuel burn for 2004 was $174.06 \mathrm{Tg}$, compared with $188.20 \mathrm{Tg}$ in 2006, which indicates that fuel burn increased from 2004 to 2006 as expected. This suggests an annual growth rate of $3.95 \%$, which agrees well with OAG and IEA data sources. The corrected speciated emissions for 2004 are estimated using the new fuel burn total and the 2006 EI values from Table 1 . The 2006 and the corrected 2004 fuel burn totals match well with other recent inventory studies such as AERO2K, TRADEOFF, and FAST (Eyers et al., 2005; Lee et al., 2005; Gauss et al., 2006) as shown in Fig. 3. These and older studies have been summarized well by the ATTICA team (Lee et al., 2010). Since previous horizontal track methodologies over-predicted flight lengths, the 2006 and corrected 2004 fuel burn results represent the best estimates of global aviation consumption for these years.
Table 5. Annual emissions reported in previous SAGE study.

\begin{tabular}{|c|c|c|c|c|c|}
\hline & \multicolumn{5}{|c|}{ Previous Study Results ${ }^{a}$} \\
\hline & 2000 & 2001 & 2002 & 2003 & 2004 \\
\hline Fuel burned (Tg) & 181 & 170 & 171 & 176 & 188 \\
\hline $\mathrm{CO}_{2}-\mathrm{C}$ emissions ${ }^{\mathrm{b}}(\mathrm{Tg})$ & 156.11 & 146.28 & 147.10 & 152.01 & 162.11 \\
\hline $\mathrm{NO}_{2}$ emissions $^{\mathrm{c}}(\mathrm{Tg})$ & 2.510 & 2.350 & 2.410 & 2.490 & 2.690 \\
\hline
\end{tabular}

a Data from (Kim, 2005);

b carbon from $\mathrm{CO}_{2}$ obtained by molecular weight ratio: $M_{\mathrm{C}} / M_{\mathrm{CO}_{2}}$; ${ }^{c} \mathrm{NO}_{\mathrm{x}}$ Converted to $\mathrm{NO}_{2}$ in database.

\subsection{Temporal emissions}

Figure 4 a shows the daily annual carbon from $\mathrm{CO}_{2}$ emissions $\left(\mathrm{CO}_{2}-\mathrm{C}\right)$ for 2004 and 2006. Since most emissions occurred in the Northern Hemisphere, the annual temporal distribution was dominated by the Northern Hemisphere seasons. Air travel increased in early April and continued through October and dropped off during the winter. The increase in air traffic in summer led to a peak in daily emissions from July through August. Mid-winter activity dropped to a low in January and February. However, the 2004 data set contains an artificial over-count of operations all year and a daylight savings coding error is evident from April through October. 


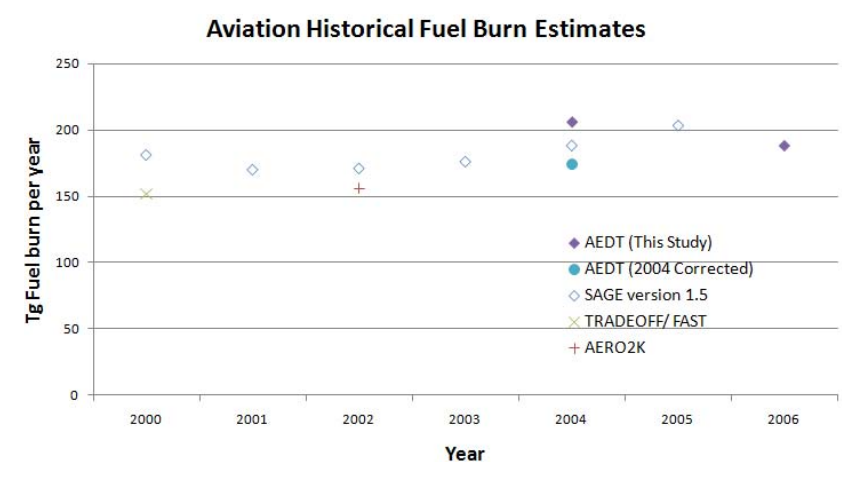

Fig. 3. Fuel burn estimates by year from recent studies: TRADEOFF, FAST, AERO2K, SAGE 1.5 compared with current AEDT results.

For flight schedule information, radar-based (ETMS) and schedule based (OAG) were pulled together globally. The attempt to merge these data sources was not perfect and resulted in some double-counts throughout the year, primarily over North America where radar coverage occurred. This over-count was also present in the previous SAGE emissions report referred to above. While most of the difference between the current corrected 2004 study and the older 2004 SAGE study represents the difference in track methodologies, a smaller undetermined amount is a combination of this underlying double-count and the continual improvements to the database.

During daylight savings period, a bug in the merging resulted in a much more significant double-count during these months. We can estimate the daylight savings error by estimating the effect of the jump in emissions in each of the seven months. From Fig. 4a, the uncorrected $2004 \mathrm{CO}_{2}-$ $\mathrm{C}$ daily mean emissions are about $0.01 \mathrm{Tg}$ per day higher than computed for 2006 during non-daylight savings months. Taking this into account when comparing the two curves: uncorrected 2004 data are about 14\% higher than expected in April and May, $13 \%$ higher in June, $8 \%$ higher in July and August, and $11 \%$ higher in September and October. Combined, the daylight savings portion of the over-count is estimated at about $6.2 \%$ or $11 \mathrm{Tg}$ of $\mathrm{CO}_{2}-\mathrm{C}$ for the year. Subtracting this daylight savings error reduces the reported 2004 $\mathrm{CO}_{2}$-C emissions to about $166 \mathrm{Tg}$ globally. After subtracting the daylight saving error, there still remains a smaller overcount of undetermined amount. The remaining difference between the two reports is a combination of the inclusion of unscheduled flights and other regular improvements in the process.

The known over-counts were resolved before the 2006 data were computed, by using ETMS exclusively in regions where radar coverage occurred (primarily North America). Thus, the 2006 data set more accurately captures seasonal trends, with peak operation count in the Northern Hemisphere summer months and lowest during the winter months.
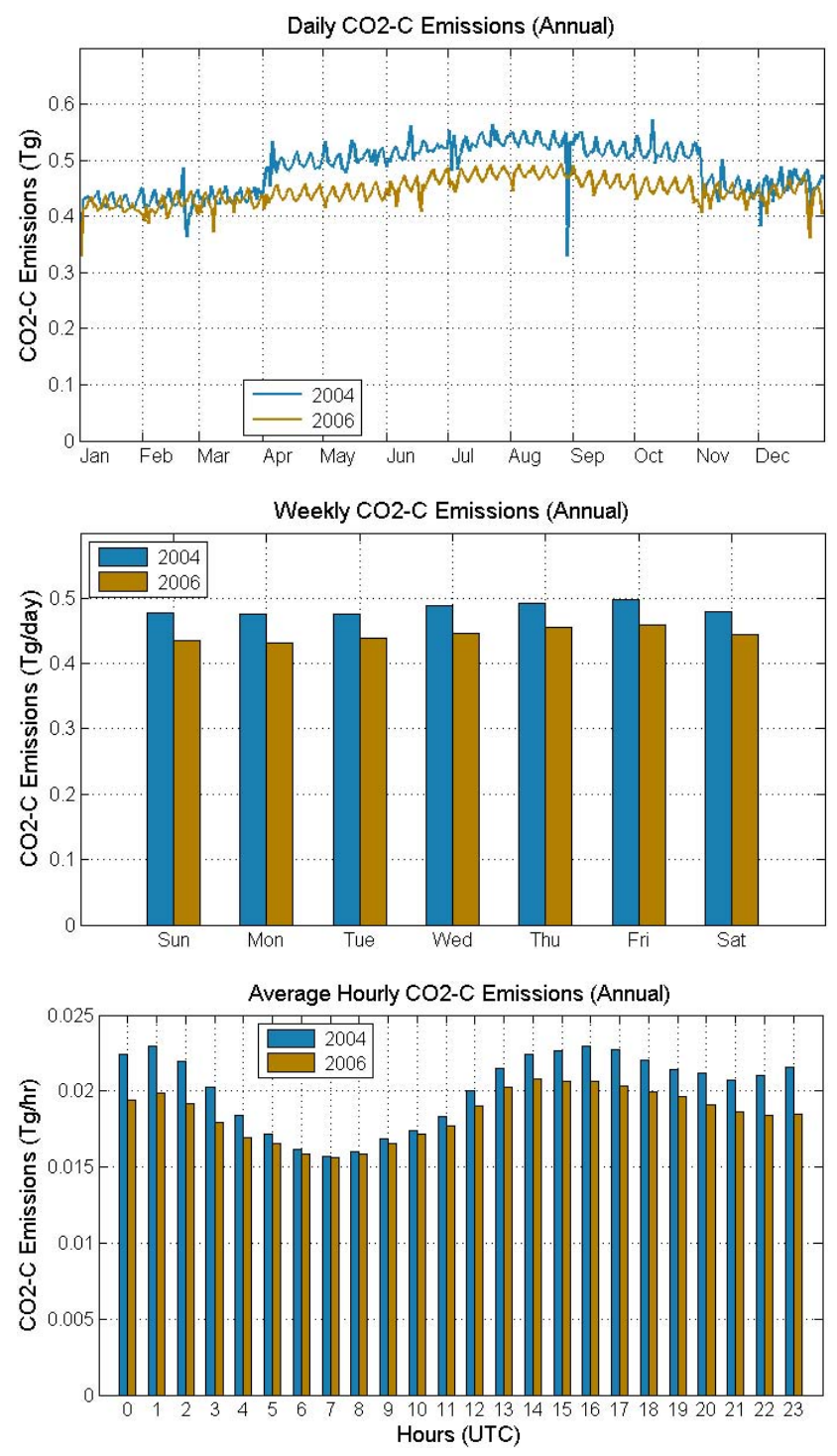

Fig. 4. Annual 2004 (uncorrected) and $2006 \mathrm{CO}_{2}-\mathrm{C}$ emissions. (a) total daily emissions, (b) total emissions per day of the week, (c) average contributions for each hour of the day.

Again, the data here should not be used to indicate emissions trends between 2004 and 2006, but the results here are useful to researchers already using either dataset for global or regional climate studies.

The daily emission curves in Fig. 4a show an oscillation which illustrates the weekly periodicity. Integrating all emissions by day of the week shows aviation activity peaked on Thursday and Friday and dropped off for the weekend (Fig. 4b). The daily and weekly profiles were tallied relative to Universal Time Coordinate (UTC), which led to an investigation of emission contributions by the hour. A compilation of the hourly global data resulted in the 24-h profile in Fig. $4 c$, which shows annual average emissions per hour. The over-counts affected primarily North America were radar 

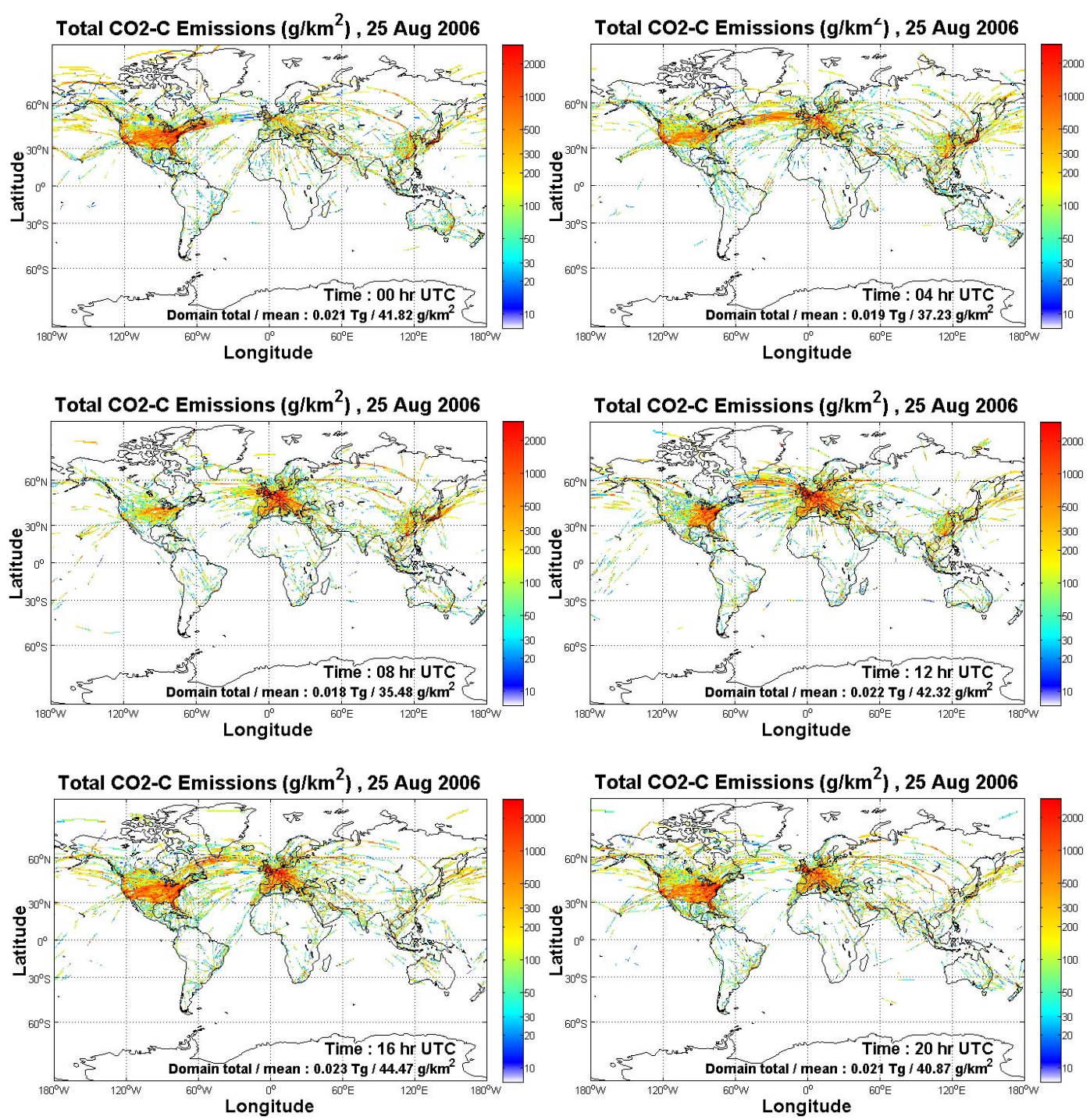

Fig. 5. Composite of hourly column $\mathrm{CO}_{2}-\mathrm{C}$ emissions through the daily cycle on 25 August, 2006. Time is measured relative to UTC. Activity at 00:00-UTC shows evening traffic in Asia. As time progresses, morning rush hours in Europe, then the United States are evident. Toward the end of the day in the US, activity moves over the Pacific toward Asia and redeye flights back to Europe to start the cycle over again.

coverage existed, which is evident by the behavior of the 2004 hourly emissions curve in Fig. 4c. As shown earlier, less fuel was, in fact, burned in 2004 than in 2006. It follows that comparisons between the two years should also show less per day or per hour than in 2006. That said, as activity rapidly increased in North America, beginning around 12:00 UTC, the 2004 curve increases faster than the 2006 curve; thus, indicating the over count is embodied primarily in North American activity. This evidence does not show up in Fig. 4b, since the data were aggregated by day.
The composite image in Fig. 5 shows the integrated annual emissions incrementally through the day, again relative to UTC. Hour 00:00 UTC is midnight in London, and afternoon in Asia where the industry is still very active. Over the next several hours, planes from Asia begin making their way toward Europe and arrive in time for the local morning rush hour. By hour 08:00 UTC, rush hour in Great Britain has ensued and aviation activity over Europe is increasing quickly. 12:00 UTC is 07:00 a.m. Eastern Standard Time along the US Eastern Seaboard; and aircraft racing across the North Atlantic join an increasing amount of aircraft originating in Eastern US. Over the next three hours, the rest of North America begins to add to aircraft activity as Europe begins to slow down at the end of the work day. Toward the 
Table 6. Flight length and duration for 2006 short-haul and long-haul flights.

\begin{tabular}{|c|c|c|c|}
\hline Global Statistics for 2006 & Total & Percent of Total & \\
\hline \multicolumn{4}{|l|}{ Total $(100 \%)$} \\
\hline & Distance traveled (Billion km) & 38.68 & $100.00 \%$ \\
\hline & Total number of flights (Million) & 31.26 & $100.00 \%$ \\
\hline & $\mathrm{CO}_{2}-\mathrm{C}$ emissions ${ }^{a}(\mathrm{Tg})$ & 162.25 & $100.00 \%$ \\
\hline & Average flight length $(\mathrm{km})$ & 1237.19 & \\
\hline & Average flight time (hr) & 2.06 & \\
\hline & $\mathrm{CO}_{2}-\mathrm{C}$ emissions $(\mathrm{kg} / \mathrm{km})$ & 4.20 & \\
\hline \multicolumn{4}{|c|}{ Short-Haul (Less than $3 \mathrm{~h}$ flight time) } \\
\hline & Distance traveled (Billion km) & 20.85 & $53.92 \%$ \\
\hline & Total number of flights (Million) & 26.62 & $85.17 \%$ \\
\hline & $\mathrm{CO}_{2}-\mathrm{C}$ emissions $(\mathrm{Tg})$ & 64.34 & $39.65 \%$ \\
\hline & Average flight length $(\mathrm{km})$ & 783.28 & \\
\hline & Average flight time (hr) & 1.50 & \\
\hline & $\mathrm{CO}_{2}-\mathrm{C}$ emissions $(\mathrm{kg} / \mathrm{km})$ & 3.09 & \\
\hline \multicolumn{4}{|c|}{ Medium-Haul (Between 3 and $6 \mathrm{~h}$ flight time) } \\
\hline & Distance traveled (Billion km) & 9.61 & $24.85 \%$ \\
\hline & Total number of flights (Million) & 3.48 & $11.15 \%$ \\
\hline & $\mathrm{CO}_{2}-\mathrm{C}$ emissions $(\mathrm{Tg})$ & 36.74 & $22.65 \%$ \\
\hline & Average flight length $(\mathrm{km})$ & 2759.01 & \\
\hline & Average flight time (hr) & 3.96 & \\
\hline & $\mathrm{CO}_{2}-\mathrm{C}$ emissions $(\mathrm{kg} / \mathrm{km})$ & 3.82 & \\
\hline \multicolumn{4}{|c|}{ Long-Haul (More than $6 \mathrm{~h}$ flight time) } \\
\hline & Distance traveled (Billion km) & 8.21 & $21.23 \%$ \\
\hline & Total number of flights (Million) & 1.15 & $3.69 \%$ \\
\hline & $\mathrm{CO}_{2}-\mathrm{C}$ emissions $(\mathrm{Tg})$ & 61.17 & $37.70 \%$ \\
\hline & Average flight length $(\mathrm{km})$ & 7117.94 & \\
\hline & Average flight time (hr) & 9.28 & \\
\hline & $\mathrm{CO}_{2}-\mathrm{C}$ emissions $(\mathrm{kg} / \mathrm{km})$ & 7.45 & \\
\hline
\end{tabular}

${ }^{\text {a }}$ Carbon from $\mathrm{CO}_{2}$ obtained by molecular weight ratio: $M_{\mathrm{C}} / M_{\mathrm{CO}_{2}}$.

end of the day in the US, aircraft along the east coast begin red-eye flights toward Europe, and aircraft along the Pacific coast head out over the Pacific Ocean toward Asia where the activity starts all over again the next day.

\subsection{Global $\mathrm{CO}_{2}-\mathrm{C}$ emissions}

The 2006 dataset describes 31.26 million flights travelling a total of 38.68 billion $\mathrm{km}$, emitting about $162.25 \mathrm{Tg}$ of carbon from $\mathrm{CO}_{2}\left(\mathrm{CO}_{2}-\mathrm{C}\right)$. These emissions represent about 2$3 \%$ of global anthropogenic $\mathrm{CO}_{2}$ emissions (Sausen et al., 2005). In 2006, the total mean flight was $1237.19 \mathrm{~km}$ and $2.06 \mathrm{~h}$, which is only slightly longer than a typical flight between San Francisco and Los Angeles, California. This indicates the dataset is dominated by short-haul flights which, by one definition, are those that are less than three hours in duration. Long-haul flights are those lasting more than six hours, and flights lasting between three and six hours are considered medium-haul flights. Aggregating the data by these rules provides the results in Table 6. Short-haul flights represent $85.17 \%$ of the total number of flights. This is il-

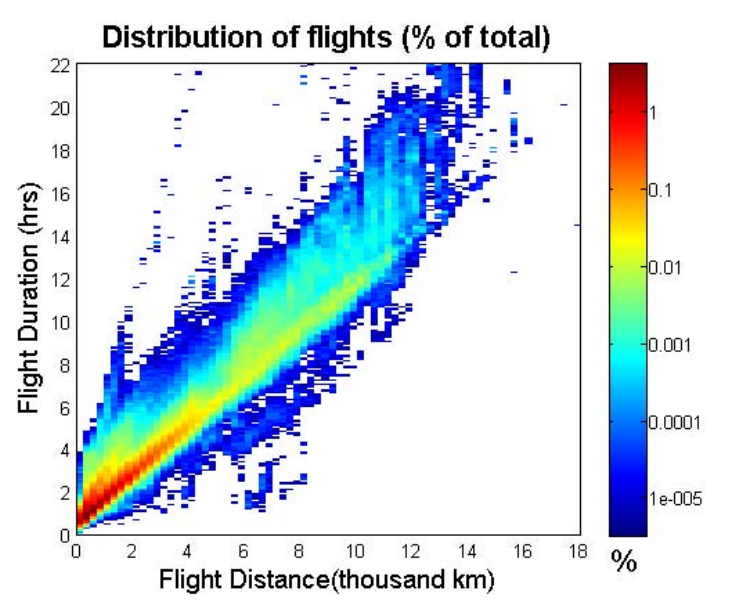

Fig. 6. Percent distribution of all flights for 2006. There are some suspect flights in the data that cover 6-10 thousand $\mathrm{km}$ in only a few hours, as well as those that take many hours to cover relatively short distances; however these represent an extremely small fraction of the data. 
Total $\mathrm{CO}_{2}-\mathrm{C}$ Emissions $\left(\mathrm{kg} / \mathrm{km}^{2}\right)$, Annual 2006
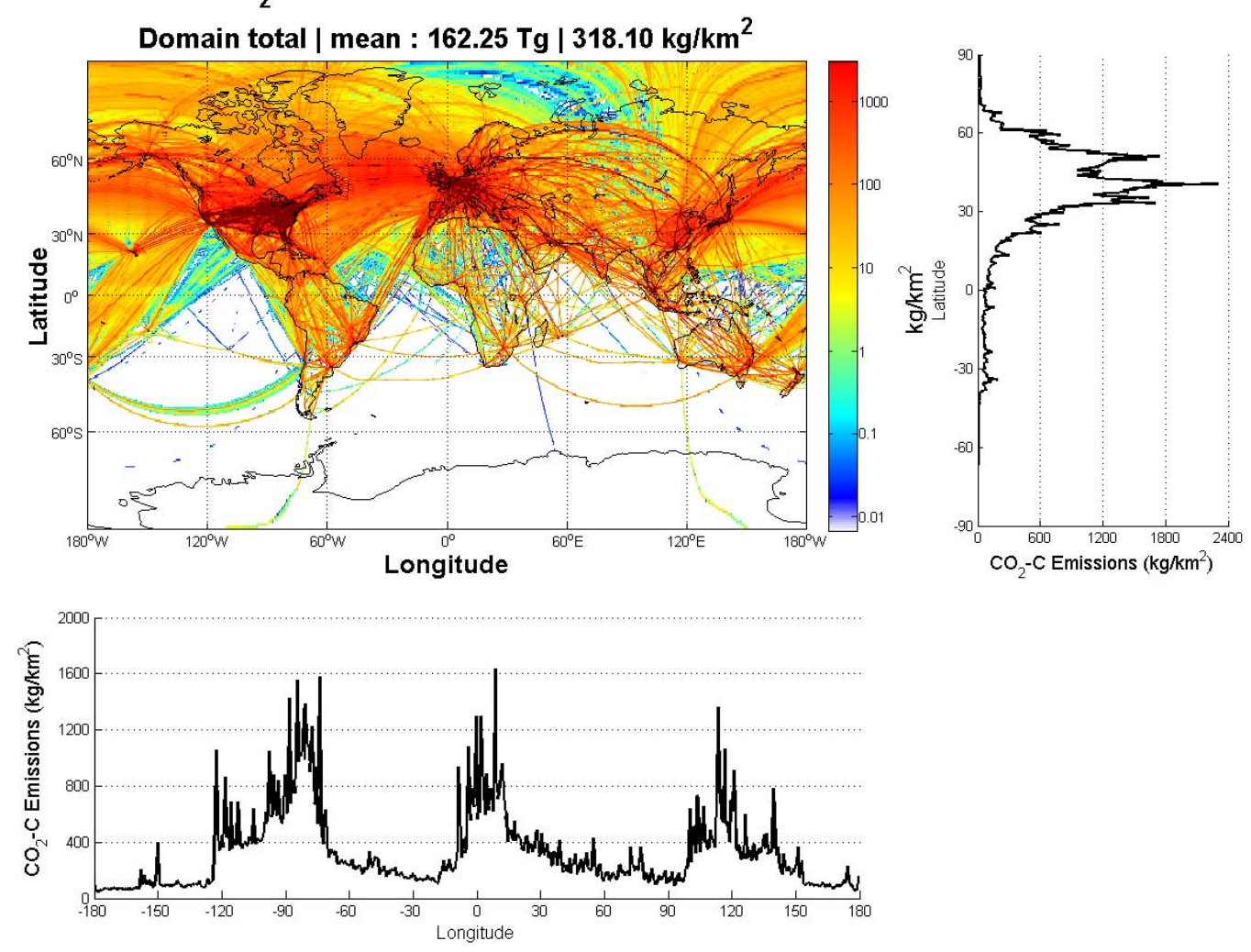

Fig. 7. Spatial distribution of carbon emissions in $\mathrm{CO}_{2}$. (a) Global column total; (b) Latitude profile; (c) Longitude profile.

lustrated in the length-duration plot in Fig. 6, which shows the percentage of flights for a given distance and duration bin. Short-haul flights account for about half (53.92\%) of the total annual distance travelled by all commercial aviation and emit $39.65 \%$ of the total $\mathrm{CO}_{2}-\mathrm{C}$. By contrast, long-haul flights emit about the same total $\mathrm{CO}_{2}-\mathrm{C}(37.70 \%)$; yet they account for only $3.69 \%$ of the total number of flights and $21.23 \%$ of total distance travelled annually. Long-haul aircraft must carry the fuel for a longer mission; this weight leads to more fuel burn and twice the rate of emissions of an average short-haul flight.

Figure 7 illustrates annual 2006 carbon emissions from $\mathrm{CO}_{2}$, which was $2-3 \%$ of total anthropogenic $\mathrm{CO}_{2}-\mathrm{C}$ emissions. Not surprisingly, it is very much like the fuel burn footprint for the same year. However, the data are presented here as emissions per unit area to better understand some of the regional effects described in Sect. 3.4 below. Latitude and Longitude zonal profiles are included with the figure. The latitude plot (Fig. 7b) shows the disparity between Northern and Southern Hemisphere emissions, with a peak of nearly $2400 \mathrm{~kg} / \mathrm{km}^{2} \mathrm{CO}_{2}-\mathrm{C}$ occurring around $40^{\circ} \mathrm{N}$. The longitude plot (Fig. 7c) highlights three regions of significant activity that account for more than half of the global $2006 \mathrm{CO}_{2}-\mathrm{C}$ emissions: the United States, Europe, and East Asia.
All three of these primary regions, and the dominant flight corridors between them, occur in the Northern Hemisphere and almost entirely within northern mid latitudes. Weather circulation patterns in the lower latitudes do not often exchange between the Northern and Southern Hemispheres, and winds in the mid latitudes are typically strong and spread emissions in this region quickly (Zhao and $\mathrm{Li}, 2006$ ). Thus, since these three regions enjoy the predominant share of aviation activity, they also suffer from the majority of global aviation emissions and subsequent effects.

The provided AEDT flight data are with respect to mean sea level (MSL), assuming an international standard atmosphere pressure profile. Emissions at altitudes above $7 \mathrm{~km}$ can be considered cruise-related emissions, while those below $7 \mathrm{~km}$ include shorter flights and local emissions associated with airport activity such as taxi, take-off, and landing. $74.6 \%$ of all aviation fuel was burned above $7 \mathrm{~km}$, where emissions have a longer residence time than those emitted near the surface. The global vertical profile of $2006 \mathrm{CO}_{2-}$ $\mathrm{C}$ emissions (Fig. 8a) shows some activity near zero MSL, which is associated with airport activity and take-off/landing. There is a gradual increase in emissions up through $7 \mathrm{~km}$, then a dramatic increase above $9 \mathrm{~km}$. Peak emissions occurred between $10-12 \mathrm{~km}$ in the upper troposphere and lower stratosphere (UTLS) where contrails predominantly form. 
Table 7. IPCC Regional $\mathrm{CO}_{2}-\mathrm{C}$ Emissions for 2004 (uncorrected) and 2006.

\begin{tabular}{|c|c|c|c|c|c|c|c|c|c|}
\hline & \multirow[b]{2}{*}{ IPCC Region } & \multicolumn{4}{|c|}{2004 (uncorrected) } & \multicolumn{4}{|c|}{2006} \\
\hline & & $\mathrm{CO}_{2}-\mathrm{C}^{\mathrm{a}}(\mathrm{Tg})$ & $\%$ Total & $\mathrm{kg} / \mathrm{km}^{2}$ & Above $7 \mathrm{~km}$ & $\mathrm{CO}_{2}-\mathrm{C}^{\mathrm{a}}(\mathrm{Tg})$ & $\%$ Total & $\mathrm{kg} / \mathrm{km}^{2}$ & Above $7 \mathrm{~km}$ \\
\hline 0 & OCEAN & 35.05 & $19.79 \%$ & 107 & $98.7 \%$ & 29.99 & $18.48 \%$ & 92 & $99.2 \%$ \\
\hline 1 & CANADA & 9.56 & $5.40 \%$ & 756 & $87.6 \%$ & 6.80 & $4.19 \%$ & 538 & $87.5 \%$ \\
\hline 2 & USA & 50.72 & $28.64 \%$ & 4,383 & $66.6 \%$ & 41.77 & $25.74 \%$ & 3609 & $65.1 \%$ \\
\hline 3 & CENTRAL AMERICA & 4.43 & $2.50 \%$ & 827 & $66.7 \%$ & 3.26 & $2.01 \%$ & 610 & $68.6 \%$ \\
\hline 4 & SOUTH AMERICA & 5.04 & $2.85 \%$ & 248 & $72.2 \%$ & 4.28 & $2.64 \%$ & 211 & $68.2 \%$ \\
\hline 5 & NORTHERN AFRICA & 1.42 & $0.80 \%$ & 216 & $84.2 \%$ & 1.57 & $0.97 \%$ & 239 & $75.7 \%$ \\
\hline 6 & WESTERN AFRICA & 1.23 & $0.69 \%$ & 101 & $83.4 \%$ & 1.21 & $0.74 \%$ & 99 & $79.7 \%$ \\
\hline 7 & EASTERN AFRICA & 0.75 & $0.43 \%$ & 108 & $82.5 \%$ & 0.76 & $0.47 \%$ & 109 & $80.6 \%$ \\
\hline 8 & SOUTHERN AFRICA & 1.01 & $0.57 \%$ & 130 & $74.2 \%$ & 1.06 & $0.65 \%$ & 137 & $71.6 \%$ \\
\hline 9 & OECD EUROPE & 22.52 & $12.71 \%$ & 3507 & $63.2 \%$ & 23.95 & $14.76 \%$ & 3730 & $60.0 \%$ \\
\hline 10 & EASTERN EUROPE & 2.67 & $1.51 \%$ & 2,146 & $89.8 \%$ & 3.55 & $2.19 \%$ & 2847 & $86.0 \%$ \\
\hline 11 & FORMER USSR & 10.22 & $5.77 \%$ & 406 & $91.2 \%$ & 8.12 & $5.00 \%$ & 323 & $92.3 \%$ \\
\hline 12 & MIDDLE EAST & 5.35 & $3.02 \%$ & 752 & $77.1 \%$ & 6.10 & $3.76 \%$ & 858 & $71.6 \%$ \\
\hline 13 & SOUTH ASIA & 3.55 & $2.01 \%$ & 586 & $81.5 \%$ & 4.36 & $2.69 \%$ & 719 & $78.8 \%$ \\
\hline 14 & EAST ASIA & 10.45 & $5.90 \%$ & 868 & $74.4 \%$ & 11.70 & $7.21 \%$ & 971 & $68.3 \%$ \\
\hline 15 & SOUTHEAST ASIA & 5.50 & $3.11 \%$ & 575 & $69.4 \%$ & 5.76 & $3.55 \%$ & 601 & $63.9 \%$ \\
\hline 16 & OCEANIA & 3.26 & $1.84 \%$ & 249 & $71.3 \%$ & 3.31 & $2.04 \%$ & 254 & $68.9 \%$ \\
\hline 17 & JAPAN & 3.86 & $2.18 \%$ & 4071 & $55.6 \%$ & 4.45 & $2.74 \%$ & 4694 & $56.8 \%$ \\
\hline 18 & GREENLAND & 0.49 & $0.28 \%$ & 181 & $99.3 \%$ & 0.25 & $0.15 \%$ & 90 & $99.5 \%$ \\
\hline \multirow[t]{2}{*}{19} & ANTARCTICA & 0.00092 & $0.0005 \%$ & 0.0625 & $100.0 \%$ & 0.00061 & $0.0004 \%$ & 0.0415 & $100.0 \%$ \\
\hline & Global Totals & 177.09 & $100.00 \%$ & 347.20 & $77.1 \%$ & 162.25 & $100.00 \%$ & 318.10 & $74.6 \%$ \\
\hline
\end{tabular}

${ }^{\text {a }}$ Carbon from $\mathrm{CO}_{2}$ obtained by molecular weight ratio: $M_{\mathrm{C}} / M_{\mathrm{CO}_{2}}$.
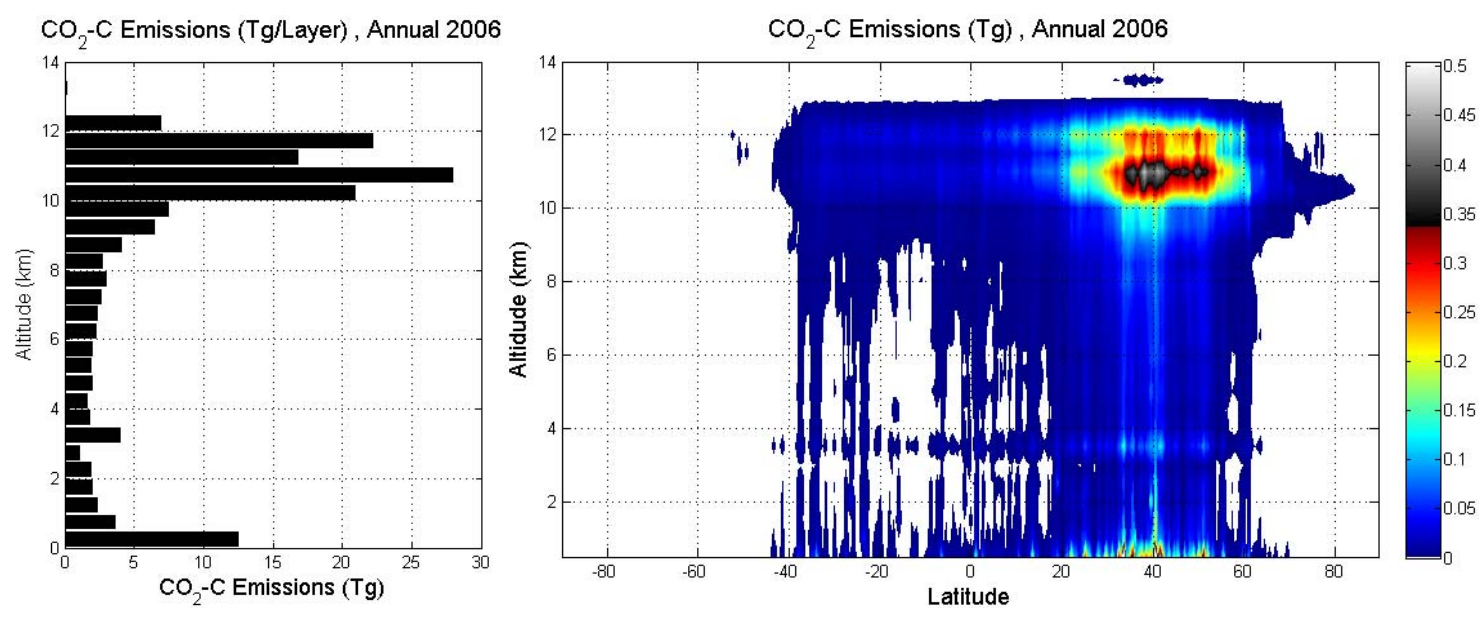

Fig. 8. Altitude profile of and altitude-latitude zonal plot of 2006 annual $\mathrm{CO}_{2}-\mathrm{C}$ emissions.

An interesting double peak occurs in the UTLS, which can be attributed to East-West and North-South flight clearance altitudes for safe passing. The altitude zonal plot (Fig. 8b) shows the bulk of emissions occurred over the northern mid latitudes; emissions in this region predominantly occur below the mean tropopause where they will contribute to tropospheric weather patterns and cloud formation.

\subsection{Regional $\mathrm{CO}_{2}-\mathrm{C}$ emissions}

Table 7 lists the $\mathrm{CO}_{2}-\mathrm{C}$ emissions for each of the IPCC SRES regions, as well as the percent of the regional emissions that occurred above $7 \mathrm{~km}$. These are emissions occurring within the boundaries of each region without regard for origination or destination of the air traffic. Despite covering only $2.27 \%$ of the total surface area, $25.74 \%$ of the emissions occurred within the US borders (including Alaska) in 2006. 
Table 8. Box Region $\mathrm{CO}_{2}-\mathrm{C}$ Emissions.

\begin{tabular}{|c|c|c|c|c|c|c|c|c|c|}
\hline & \multirow[b]{2}{*}{ Box Region } & \multicolumn{4}{|c|}{2004 (Uncorrected) } & \multicolumn{4}{|c|}{2006} \\
\hline & & $\mathrm{CO}_{2}-\mathrm{C}^{\mathrm{a}}(\mathrm{Tg})$ & $\%$ Total $^{\mathrm{b}}$ & $\mathrm{kg} / \mathrm{km}^{2}$ & Above $7 \mathrm{~km}$ & $\mathrm{CO}_{2}-\mathrm{C}^{\mathrm{a}}(\mathrm{Tg})$ & $\%$ Total $^{\mathrm{b}}$ & $\mathrm{kg} / \mathrm{km}^{2}$ & Above $7 \mathrm{~km}$ \\
\hline $\mathrm{A}$ & United States & 55.68 & $31.44 \%$ & 3549 & $68.7 \%$ & 45.18 & $25.51 \%$ & 2880 & $67.2 \%$ \\
\hline B & Eastern US & 33.98 & $19.19 \%$ & 4407 & $65.8 \%$ & 27.43 & $15.49 \%$ & 3558 & $64.2 \%$ \\
\hline $\mathrm{C}$ & Western US & 21.70 & $12.25 \%$ & 2720 & $73.3 \%$ & 17.75 & $10.02 \%$ & 2225 & $71.7 \%$ \\
\hline $\mathrm{D}$ & Arctic Region & 2.44 & $1.38 \%$ & 115.6 & $97.2 \%$ & 1.14 & $0.64 \%$ & 53.9 & $95.2 \%$ \\
\hline $\mathrm{E}$ & Europe & 24.75 & $13.97 \%$ & 3733 & $67.9 \%$ & 25.82 & $14.58 \%$ & 3895 & $64.4 \%$ \\
\hline $\mathrm{F}$ & Eastern Asia & 17.79 & $10.05 \%$ & 1103 & $75.1 \%$ & 19.57 & $11.05 \%$ & 1214 & $71.3 \%$ \\
\hline G & NAFC & 13.94 & $7.87 \%$ & 1220 & $96.8 \%$ & 11.46 & $6.47 \%$ & 1003 & $96.9 \%$ \\
\hline \multirow[t]{2}{*}{$\mathrm{H}$} & NPFC & 12.85 & $7.25 \%$ & 545 & $49.9 \%$ & 11.15 & $6.30 \%$ & 473 & $47.5 \%$ \\
\hline & Global Totals & 177.09 & $100.00 \%$ & 347.20 & $77.1 \%$ & 162.25 & $100 \%$ & 318.10 & $74.6 \%$ \\
\hline
\end{tabular}

${ }^{\text {a }}$ Carbon from $\mathrm{CO}_{2}$ obtained by molecular weight ratio: $M_{\mathrm{C}} / M_{\mathrm{CO}_{2}}$;

$\mathrm{b}$ column does not sum to $100 \%$.

Differences in track methodologies employed by AEDT between 2004 and 2006 inventories will not allow a quantitative comparison of spatial emissions; however, these differences can drive significant regional variations. For example, in Eastern Europe, Table 7 shows emissions increased significantly, whereas emissions in neighboring former USSR exhibited similar numerical decrease. The 2006 inventory included data from ETFMS, which includes Eastern Europe; thus, greatly expanding radar-provided schedule and flight data. By including ETFMS, which enabled the use of more airways tracks instead of GC dispersion estimates, Eastern Europe was more comprehensively represented in 2006, compared with 2004. Again, the methodology used for the 2006 data set is considered a more accurate representation of actual flight trajectories. The over-count in the 2004 data set predominately affects ETMS radar flights over North America, so such comparisons of regional emissions, especially over Europe, are appropriate.

The Box regions are slightly larger than similar IPCC regions, which allow for less dependence of results on horizontal track estimation methods. The purpose of these regions is to highlight areas of significant aviation activity. From the global longitudinal profile in Fig. 7c, it is apparent that the continental US receives more emissions than any other region $(25.5 \%)$, followed closely by Europe (14.6\%) and then Eastern Asia (11.1\%). These three regions account for only $7.5 \%$ of global surface area, but receive over half, $51.1 \%$, of all aviation $\mathrm{CO}_{2}-\mathrm{C}$ emissions. These and other regions are summarized in Table 8.

Unlike the SRES US region, the US box region is essentially the continental US but includes activity surrounding its borders. This region received about one quarter of all global emissions in 2006. Emissions within the region were dominant in the eastern half of the country, which has more airports and a larger population than the western half. Splitting the region evenly into east and west illustrates the eastern dominance: the Eastern US region receives about two thirds of the US emissions with a concentration of more than 11 times the 2006 global average emissions concentration. The Highest concentration of emissions is over Europe, which receives more than 12 times the global average concentration. There is no evident east-west inflection in the European profile, so this region was not sub-divided; however, the northern part of the region does see slightly more activity.

The East Asia box region encompasses about the same area as the US box, but received less than half of emissions when compared with the US box. The activity was predominantly along a Northeast-Southwest orientation. China's reported aviation activity grew at an average of $14.5 \%$ per year through 2007 (CAAC, 2009). Whether this is entirely growth or partially from increased accountability, aviation activity and subsequent emissions within this region are expected to continue growing over the next few years.

The global footprint also shows two dominant flight corridors: North Atlantic and North Pacific Flight Corridors (NAFC, NPFC). The NAFC box captures the dominant traffic exchange between Europe and the US. The NPFC box covers a larger area so the analysis is less effective when isolated within a single rectangular box. Despite this expansive coverage, there are still other regular Pacific flight corridors which were not captured within the box, such as between Japan and Hawaii. Comparing the NAFC and NPFC, more total kilometers were flown within the NPFC bounds, but the NAFC received nearly two times higher concentration of $\mathrm{CO}_{2}-\mathrm{C}$ emissions. Also, only a third of the NPFC emissions occurred above $7 \mathrm{~km}$, while nearly all of the NAFC emissions occurred above $7 \mathrm{~km}$. These and other totals are shown in Table 8.

Another region of interest is the Arctic. The total emissions over this region during 2006 were about $0.64 \%$ of the global total, resulting in a mean emission concentration about $1 / 6$ per unit area as the global mean. Yet, in 2004, the 
Table 9. Speciation profile for emitted hydrocarbons (FAA, 2008).

\begin{tabular}{|c|c|c|c|c|c|}
\hline Species & Mass Fraction & Species & Mass Fraction & Species & Mass Fraction \\
\hline Ethylene & 0.15459 & 1-Nonene & 0.00246 & Methanol & 0.01805 \\
\hline Acetylene & 0.03939 & n-Nonane & 0.00062 & Formaldehyde (FAD) & 0.12308 \\
\hline Ethane & 0.00521 & Isopropylbenzene & 0.00004 & Acetaldehyde (AAD) & 0.04272 \\
\hline Propylene & 0.04534 & n-Propylbenzene & 0.00067 & Acetone & 0.00369 \\
\hline Propane & 0.00078 & m-Ethyltoluene & 0.00193 & Propionaldehyde & 0.00727 \\
\hline Isobutene/1-Butene & 0.01754 & p-Ethyltoluene & 0.00080 & Crotonaldehyde & 0.01291 \\
\hline 1,3-Butadiene & 0.01687 & 1,3,5-Trimethylbenzene & 0.00068 & Butyraldehyde & 0.00148 \\
\hline cis-2-Butene & 0.00210 & o-Ethyltoluene & 0.00082 & Benzaldehyde & 0.00470 \\
\hline 3-Methyl-1-butene & 0.00140 & 1,2,4-Trimethylbenzene & 0.00438 & Isovaleraldehyde & 0.00041 \\
\hline 1-Pentene & 0.00776 & 1-Decene & 0.00185 & Valeraldehyde & 0.00306 \\
\hline 2-Methyl-1-butene & 0.00174 & n-Decane & 0.00320 & o-Tolualdehyde & 0.00287 \\
\hline n-Pentane & 0.00198 & 1,2,3-Trimethylbenzene & 0.00133 & m-Tolualdehyde & 0.00347 \\
\hline trans-2-Pentene & 0.00359 & n-Undecane & 0.00444 & p-Tolualdehyde & 0.00060 \\
\hline cis-2-Pentene & 0.00276 & n-Dodecane & 0.00462 & Methacrolein & 0.00536 \\
\hline 2-Methyl-2-butene & 0.00185 & n-Tridecane & 0.00535 & Glyoxal & 0.01816 \\
\hline 4-Methyl-1-pentene & 0.00086 & C14-alkane & 0.00186 & Methylglyoxal & 0.01503 \\
\hline 2-Methylpentane & 0.00408 & C15-alkane & 0.00177 & Acrolein & 0.02449 \\
\hline 2-Methyl-1-pentene & 0.00043 & n-tetradecane & 0.00416 & C-10 paraffins & 0.14157 \\
\hline 1-Hexene & 0.00736 & C16-alkane & 0.00146 & C-10 oleffins & 0.05663 \\
\hline trans-2-Hexene & 0.00037 & n-pentadecane & 0.00173 & Decanal & 0.05663 \\
\hline Benzene & 0.01681 & n-hexadecane & 0.00049 & Dodecenal & 0.02831 \\
\hline 1-Heptene & 0.00438 & C18-alkane & 0.00002 & & \\
\hline n-Heptane & 0.00064 & n-heptadecane & 0.00009 & & \\
\hline Toluene & 0.00642 & Phenol & 0.00726 & & \\
\hline 1-Octene & 0.00276 & naphthalene & 0.00541 & & \\
\hline n-Octane & 0.00062 & 2-methyl naphthalene & 0.00206 & & \\
\hline Ethylbenzene & 0.00174 & 1-methyl naphthalene & 0.00247 & & \\
\hline m-Xylene/p-Xylene & 0.00282 & dimethylnapthalenes & 0.00090 & & \\
\hline Styrene & 0.00309 & C4-Benzene+C3-aroald & 0.00656 & & \\
\hline o-Xylene & 0.00166 & C5-Benzene+C4-aroald & 0.00324 & & \\
\hline
\end{tabular}

Note:

Conversion factor from THC to TOG

(THC is in methane equivalent)

Turbine $\quad 1.1571$

fractional emissions and the emissions per unit area over the Arctic were twice those of 2006 (Table 8). This difference between the two years is likely due primarily to the difference between horizontal track generation methods. Flights between Europe and North America through the NAFC pass close to the Arctic Circle. If a horizontal airways track does not cross into the polar region, then none of the emissions from any flight along that trajectory can contribute to the geographical region totals. However, the dispersion method used in the 2004 data allows some of the flights between a given OD pair to pass further north and contribute to the region totals. There are several near-Arctic corridors that can contribute directly to polar emissions depending on the GC method.
Emissions over the Arctic were distributed uniformly horizontally throughout the polar region (Fig. 9), and over 95\% were emitted above $7 \mathrm{~km}$, where they have a longer residence time (due to greater stability in the upper troposphere and lower stratosphere, where Polar emissions occur) than those emitted near the surface at other latitudes. For comparison, in 2006 only $67.2 \%$ of emissions over the US and $64.4 \%$ of emissions over Europe occurred above $7 \mathrm{~km}$. Circulation patterns in the upper mid-latitudes trap polar emissions and push mid-latitude emissions further north (such as those from NAFC) into the polar region (Forster et al., 2003). Any emissions deposited within or near the Arctic Circle are likely to accumulate over the polar region, which further increases the polar emission concentrations and potential climate impacts 

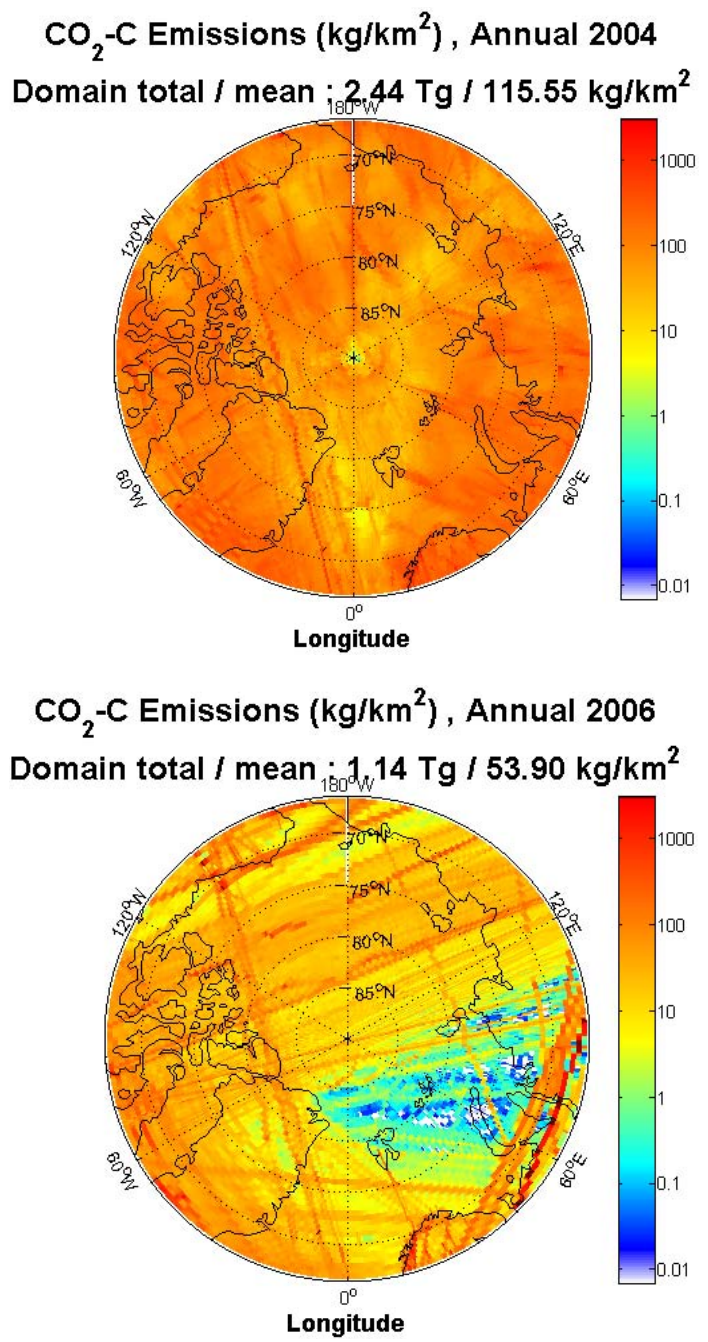

Fig. 9. Arctic aircraft $\mathrm{CO}_{2}-\mathrm{C}$ emissions per unit area for (a) 2004 (uncorrected) and (b) 2006.

on this very sensitive region. So despite different track generation methods, climate effects are likely to be similar when comparing impacts to the Arctic region.

\subsection{Other species}

In general, other emitted species have the same over-all footprint as $\mathrm{CO}_{2}-\mathrm{C}$; however, for convenience, $\mathrm{NO}_{\mathrm{x}}-\mathrm{as}_{-}-\mathrm{NO}_{2}$, $\mathrm{SO}_{\mathrm{x}}-\mathrm{S}$, and $\mathrm{BC}$ emissions are shown in Fig. 10. Within AEDT and SAGE, $\mathrm{NO}_{\mathrm{x}}$ emissions are based on the ICAO Engine Emissions Databank, which reports on an $\mathrm{NO}_{2}$ mass basis. So emissions of $\mathrm{NO}, \mathrm{NO}_{2}$, and $\mathrm{HONO}$ are reported as emissions of $\mathrm{NO}_{2}$ mass-equivalence (Kim et al., 2005b). Similarly, $\mathrm{SO}_{\mathrm{x}}$ is reported as $\mathrm{SO}_{2}$ in the database, and sulfur from $\mathrm{SO}_{2}$ is obtained by the molecular weight ratio of $\mathrm{S}$ to $\mathrm{SO}_{2}$ (0.50). Both $\mathrm{NO}_{2}$ and $\mathrm{SO}_{\mathrm{x}}-\mathrm{S}$ are proportional to fuel burn. However, $\mathrm{BC}$ emissions are also a function of engine dynamics. As described in Sect. 2.2, The BC EI used for the
Total $\mathrm{NO}_{2}$ Emissions $\left(\mathrm{kg} / \mathrm{km}^{2}\right)$, Annual 2006

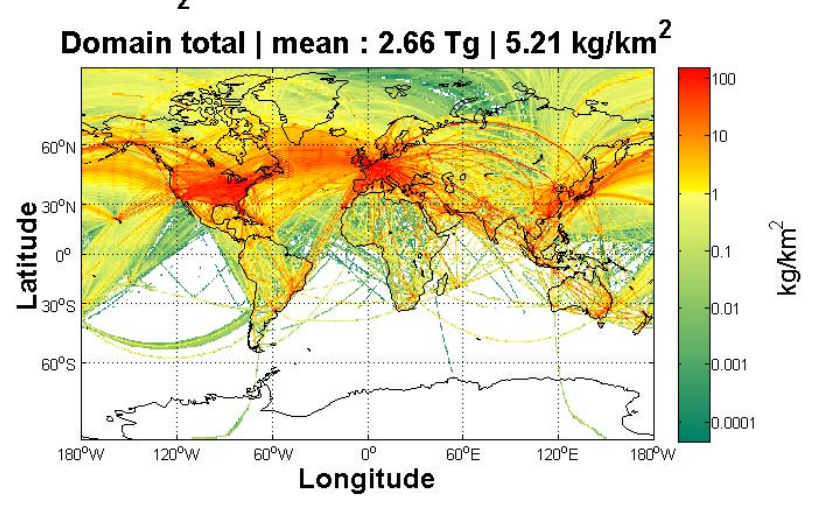

\section{Total SOx-S Emissions $\left(\mathrm{kg} / \mathrm{km}^{2}\right)$, Annual 2006 \\ Domain total | mean : $0.11 \mathrm{Tg} \mid 0.22 \mathrm{~kg} / \mathrm{km}^{2}$}

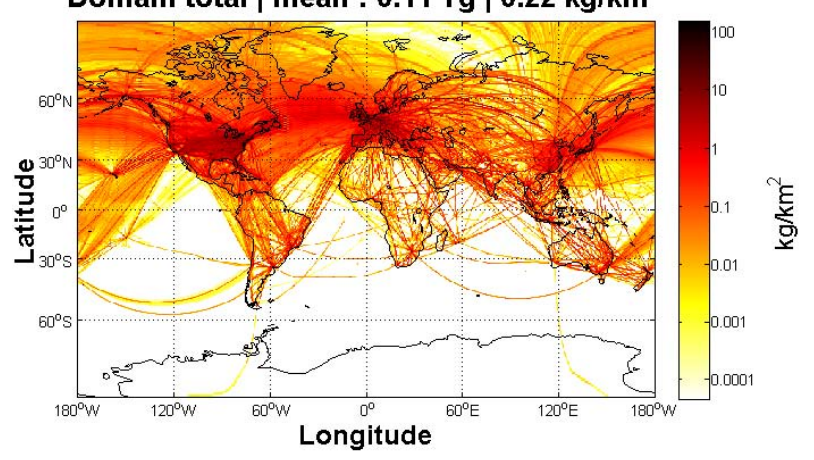

Total Black Carbon PM Emissions (kg/km²), Annual 2006
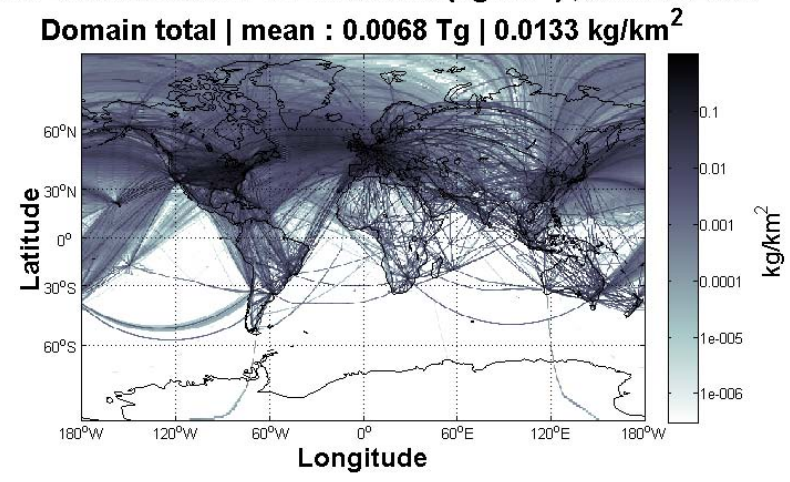

Fig. 10. Global 2006 column-integrated emissions of other species:(a) $\mathrm{NO}_{\mathrm{x}}-\mathrm{as}-\mathrm{NO}_{2}$, (b) $\mathrm{SO}_{\mathrm{x}}$, (c) Black carbon.

2006 inventory is significantly less than that used in 2004. Older inventories have used an EI equivalent to take-off and climb-out $(0.20 \mathrm{~g}-\mathrm{BC} / \mathrm{kg}$-fuel). Since $74.6 \%$ of fuel is burned above $7 \mathrm{~km}$, this BC EI most likely significantly over predicts total BC. The 2006 inventory used an EI more appropriate for cruise performance $(0.035 \mathrm{~g}$-BC/kg-fuel) which better represents $\mathrm{BC}$ emissions; however, it probably under-predicts total $\mathrm{BC}$ emissions. 
Unburned fuel or hydrocarbon emissions can be assumed to be speciated according to the turbine-engine speciation profile given in Table 9 (Knighton et al., 2009). With this profile, the bulk of hydrocarbon emissions are in the form of ethylene, formaldehyde, acetaldehyde, acetylene, propene, C-10 paraffins, C-10 olefins, decanal, dodecanal, benzene, butadiene, and butene, among others. $\mathrm{NO}_{\mathrm{x}}$ emissions speciation to NO- $\mathrm{NO}_{2}-\mathrm{HONO}$ is assumed to be a function of thrust and engine type (Wood et al., 2008).

\section{Summary}

We have analyzed global commercial aviation emissions from 2004 and 2006 in total and disaggregated by regions. In 2006, the global commercial aircraft fleet flew 31.26 million flights, burned 188.20 million metric tons of fuel and covered 38.68 billion kilometers. We have also provided corrected 2004 total fuel burn of 174.06 million metric tons, which indicates an annual growth in fuel burn of 3.95\% from 2004 to 2006. This growth rate compares well with other aviation inventories and related activity. We have also estimated the effect of an over-count error due to a daylight savings bug in uncorrected 2004 spatial data. Remaining differences between the uncorrected 2004 and 2006 results are due to methods in horizontal track generation, other methodologies and database improvements, and some residual double counting. Over-count errors occurred where there was radar coverage, primarily in North America and Western Europe.

We have shown that different horizontal track methods can impact the quantification of regional emissions and trends. When radar data are not available, AEDT employed a dispersed Great Circle method in 2004 and an airways track method in 2006, with the latter being more representative of actual flight activity.

The commercial aviation fleet emitted a total of $162.25 \mathrm{Tg}$ of $\mathrm{CO}_{2}-\mathrm{C}$ throughout 2006. The US, Europe, and Asia were subjected to $51.1 \%$ of these emissions despite covering only $7.5 \%$ of the global surface area. The global average for $\mathrm{CO}_{2}-$ $\mathrm{C}$ emissions per unit area was $318.1 \mathrm{~kg} / \mathrm{km}^{2}$ in 2006 . The Arctic received only $0.6 \%$ of the total emissions, but the per unit area emissions were about one sixth of the 2006 global average. Typical wind patterns in the upper mid-latitudes tend to trap these emissions over the arctic and push midlatitude emissions into the arctic risking significant consequences to this area of high sensitivity to climate change.

In 2006, an average flight covered $1237.2 \mathrm{~km}$ in 2.06 hours and produced $4.2 \mathrm{~kg} / \mathrm{km}$ of $\mathrm{CO}_{2}-\mathrm{C}$, which indicates a dominance of short-haul flights in the annual datasets. Short-haul flights represented $85.2 \%$ of all commercial flights and accounted for $53.9 \%$ of the total distance travelled in 2006 . These flights indicate a potential for transportation platform switching onto trains or buses. With improved pricing, policies, or incentives, existing transit systems or future high- speed rails may offer a means for offsetting a subset of these flights and the associated emissions.

We have also shown the temporal distribution of emissions on a weekly, daily and hourly basis. The seasonal peak occurred in July and August, with a decrease from November through March. During an average week, peak activity occurred on Thursday and Friday and was slowest on Monday and Tuesday. The hourly distribution of emissions was lowest at about hour 07:00 UTC and quickly ramped up through about 15:00 UTC accounting for Western European and North American rush hours. The hourly emissions remained high until the end of the Asian evening rush around 02:00-04:00 UTC.

Climate impacts from $\mathrm{CO}_{2}-\mathrm{C}$, other greenhouse gases, and particles, including from aviation have been studied significantly to date. However, the potential impacts of aviation on climate are unique since most of the emissions occur at altitudes where other anthropogenic sources are absent. The effects of aviation on stratospheric ozone and global climate from persistent contrails and contrail-induced cirrus clouds could be significant, but there are large uncertainties in relating aviation emissions to changes in radiative forcing or surface temperature from contrail-associated pathways. Knowing where the emissions occur is the first step in computing the potential impacts. Data presented here support a continuing effort to quantify the effects of aircraft exhaust on climate and global air pollution.

Acknowledgements. This work was supported by the Partnership for AiR Transportation Noise \& Emissions Reduction (PARTNER) and the Federal Aviation Administration (FAA) under award number DTFAWA-05-D=0006. Any opinions, findings, and conclusions or recommendations expressed in this material are those of the authors and do not necessarily reflect the views of PARTNER or the FAA.

Edited by: M. C. Facchini

\section{References}

Baughcum, S. L., Henderson, S. C., and Tritz, T. G.: Scheduled Civil Aircraft Emissions Inventories for 1976 and 1984: Database Development and Analysis, NASA CR 4722, 1996a.

Baughcum, S. L., Tritz, T. G., Henderson, S. C., and Pickett, D. C.: Scheduled Civil Aircraft Emissions Inventories for 1992: Database Development and Analysis, NASA CR 4700, 1996 b.

CACC: General Administration of Civil Aviation in China, China's Airlines to Carry $270 \mathrm{mln}$ Passengers in 2010, available online at: http://www.caac.gov.cn/English/News/200708/ t20070831_7717.html, last access: 19 August 2009.

DuBois, D. and Paynter, G. C.: Fuel Flow Method2 for Estimating Aircraft Emissions, SAE Technical Paper Series, Washington, DC, 2006-01-198, 2006.

Eyers, C. J., Addleton, D., Atkinson, K., Broomhead, M. J., Christou, R. A., Elliff, T. E., Falk, R., Gee, I. L., Lee, D. S., Marizy, C., Michot, S., Middel, J., Newton, P., Norman, P., Plohr, M., 
Raper, D. W., and Stanciou, N.: AERO2k Global Aviation Emissions Inventories for 2002 and 2025, QinetiQ Ltd, Farnborough, HampshireQINETIQ/04/01113, 2005.

Forster, C., Stohl, A., and James, P.: The residence times of aircraft emissions in the stratosphere using a mean emission inventory and emissions along actual flight tracks, J. Geophys. Res., 108, 8524-8535, 2003.

Gauss, M., Isaksen, I. S. A., Lee, D. S., and Søvde, O. A.: Impact of aircraft $\mathrm{NO}_{\mathrm{x}}$ emissions on the atmosphere - tradeoffs to reduce the impact, Atmos. Chem. Phys., 6, 1529-1548, doi:10.5194/acp-6-1529-2006, 2006.

Hadaller, O. J. and Momenthy, A. M.: Characteristics of Future Aviation Fuels, in: Transportation and Global Climate Change, edited by: Greene, D. L. and Santini, D. J., American Council for an Energy-Efficient Economy, Washington, DC, 1993.

ICAO, International Civil Aviation Organization, Forecasts of Scheduled Passenger Traffic: Long-Term Traffic and Aircraft Movement Forecasts, available online at: http://www.icao.int/ icao/en/atb/ead/fep/Longterm.htm, 2007.

IEA: $\mathrm{CO}_{2}$ Emissions from Fuel Combustion, Highlights (2009 Edition), International Energy Agency (IEA), 2009.

Jacobson, M. Z., Wilkerson, J. T., Naiman, A. D., and Lele, S. K.: The effects of aircraft on climate and pollution - Part 1 : A model that treats the subgrid evolution of discrete sizeand composition-resolved contrails from all commercial flights worldwide, Atmos. Chem. Phys. Discuss., submitted, 2010.

Kettunen, T., Hustache, J.-C., Fuller, I., Dan, H., Bonn, J., and Knorr, D.: Flight Efficiency Studies in Europe and the United States, 6th USA/Europe Air Traffic Management Research and Development Seminar, Baltimore, MD, 10, 2005.

Kim, B. Y., Fleming, G. G., Balasubramanian, S., Malwitz, A., Lee, J. J., Ruggiero, J., Waitz, I. A., Klima, K., Locke, M., Holsclaw, C. A., Morales, A., McQueen, E., and Gillette, W.: System for assessing Aviation's Global Emissions (SAGE) Version 1.5: System Revision History, FAA, Ed., Office of Environment and Energy, 21, 2005a.

Kim, B. Y., Fleming, G. G., Balasubramanian, S., Malwitz, A., Lee, J. J., Ruggiero, J., Waitz, I. A., Klima, K., Stouffer, V., Long, D., Kostiuk, P., Locke, M., Holsclaw, C. A., Morales, A., McQueen, E., and Gillette, W.: System for assessing Aviation's Global Emissions (SAGE) Version 1.5: Technical Manual. FAA, Ed., Office of Environment and Energy, 236, 2005 b.

Kim, B. Y., Fleming, G. G., Balasubramanian, S., Malwitz, A., Lee, J. J., Waitz, I. A., Klima, K., Locke, M., Holsclaw, C. A., Morales, A., McQueen, E., and Gillette, W.: System for assessing Aviation's Global Emissions (SAGE) Version 1.5: Global Aviation Emissions Inventories for 2000 through 2004. FAA, Ed., Office of Environment and Energy, 48, 2005c.

Kim, B. Y., Fleming, G. G., Lee, J. J., Waitz, I. A., Clarke, J.-P., Balasubramanian, S., Malwitz, A., Klima, K., Locke, M., Holsclaw, C. A., Maurice, L. Q., and Gupta, M. L.: System for assessing Aviation's Global Emissions (SAGE), Part 1: Model description and inventory results, Transport. Res. Part D: Transportation and Environment, 12D, 325-346, 2007.

Knighton, W. B., Herdon, S. C., and Miake-Lye, R. C.: Aircraft Engine Speciated Organic Gases: Speciation of Unburned Organic Gases in Aircraft Exhaust. Environmental Protection Agency, Office of Transportation and Air Quality; Federal Aviation Administration, Office of Environment and Energy, 2009.
Lee, D. S., Owen, B., Graham, A., Fichter, C., Lim, L. L., and Dimitriu, D.: Allocation of International Aviation Emissions from Scheduled Air Traffic - Present Day and Historical (Report 2 of 3), Manchester Metropolitan University, Centre for Air Transport and the Environment, Manchester, UK., 2005.

Lee, D. S., Pitari, G., Grewe, V., Gierens, K., Penner, J. E., Petzold, A., Prather, M. J., Schumann, U., Bais, A., Berntsen, T., Iachetti, D., Lim, L. L., and Sausen, R.: Transport impacts on atmosphere and climate: Aviation, Atmospheric Environment, Atmos. Environ., doi:10.1016/j.atmosenv.2009.06.005, in press, 2010.

Lee, J. J., Waitz, I. A., Kim, B. Y., Fleming, G. G., Maurice, L. Q., and Holsclaw, C. A.: System for assessing Aviation's Global Emissions (SAGE), Part 2: Uncertainty assessment, Transport. Res.; Part D: Transportation and Environment, 12D, 381-395, 2007.

Malwitz, A., Kim, B. Y., Fleming, G. G., Lee, J. J., Balasubramanian, S., Waitz, I. A., Klima, K., Locke, M., Holsclaw, C. A., Morales, A., McQueen, E., and Gillette, W.: System for assessing Aviation's Global Emissions (SAGE) Version 1.5: Assessment Validation Assessment, Model Assumptions and Uncertainties, FAA, Ed., Office of Environment and Energy, 36., 2005.

Michot, S., Elliff, T., Fleming, G. G., Kim, B. Y., Holsclaw, C. A., Locke, M., and Morales, A.: Flight Movement Inventory: SAGE-AERO2K, Air Traffic Control Quarterly, 12, 125-145, 2004.

MOCA, India Ministry of Civil Aviation; 2006-07 Annual Report: http://civilaviation.nic.in/reports/an_rep0607eng/ Chapter-1.pdf (last access: 18 July 2009), 2007.

Naiman, A. D., Lele, S. K., Wilkerson, J. T., and Jacobson, M. Z.: Parameterization of subgrid plume dilution for use in large-scale atmospheric simulations, Atmos. Chem. Phys., 10, 2551-2560, doi:10.5194/acp-10-2551-2010, 2010.

OAG: Airlines Offer Record Number Of Seats In July, available online at: http://www.oag.com/oag/website/com/en/Press+ Room/Press+Releases+2007/Airlines+Offer+Record+Number+ Of+Seats+In+July, (last access: 27 May 2010), 2007.

RIVA: The IMAGE 2.2 implementation of the SRES scenarios. A comprehensive analysis of emissions, climate change and impacts in the 21st century, National Institute for Public Health and the Environment, Bilthoven, the NetherlandsCD-ROM publication 481508018, 2001.

Roof, C., Hansen, A., Fleming, G. G., Thrasher, T., Nguyen, A., Hall, C., Dinges, E., Bea, R., Grandi, F., Kim, B. Y., Usdrowski, S., and Hollingsworth, P.: Aviation Environmental Design Tool (AEDT) System ArchitectureAEDT-AD-01, 2007.

Sausen, R., Isaksen, I. S. A., Grewe, V., Hauglustaine, D., Lee, D. S., Myhre, G., Kohler, M. O., Pitari, G., Schumann, U., Stordal, F., and Zerefos, C. S.: Aviation radiative forcing in 2000: An update on IPCC (1999), Meteorol. Z., 14, 555-561, 2005.

Sutkus Jr., D. J., Baughcum, S. L., and DuBois, D. P.: Scheduled Civil Aircract Emission Inventories for 1999: Database Development and Analysis, NASA-CR-2001-211216, 2001.

Volpe: Volpe National Transportation Systems Center/US DOT, Enhanced Traffic Management System (ETMS), Functional Description, Version 7.6VNTSC-DTS56-TMS-002, 2003.

Waitz, I. A., Lukachko, S. P., and Lee, J. J.: Military Aviation and the Environment: Historical Trends and Comparison to Civil Aviation, J. Aircraft, 42, 329-339, 2005. 
Wayson, R. L., Fleming, G. G., and Lovinelli, R.: Methodology to Estimate Particulate Matter Emissions from Certified Commercial Aircraft Engines, J. Air Waste Manage. Assoc., 59, 91-100, 2009.

Whitefield, P. D., Lobo, P., Hagen, D. E., Timko, M. T., Miake-Lye, R. C., Taylor, C., Ratliff, G., Lukachko, S., Sequeira, C., Hileman, J., Waitz, I. A., Webb, S., Thrasher, T. G., Oshfeldt, M. R., Kaing, H. K., and Essama, S. G.: Summarizing and Interpreting Aircraft Gaseous and Particulate Emissions Data, Aircraft Cooperative Research Program, Report 9, Transportation Research Board, Washington, DC, 2008.
Wood, E. C., Herdon, S. C., Timko, M. T., Yelvington, P. E., and Miake-Lye, R. C.: Speciation and Chemical Evolution of Nitrogen Oxides in Aircraft Exhaust near Airports, Environ. Sci. Technol., 42, 1884-1891, 2008.

Zhao, Y. and Li, J.: Discrepancy of mass transport between the Northern and Southern Hemispheres among the ERA-40, NCEP/NCAR, NCEP-DOE AMIP-2, and JRA-25 reanalysis, Geophys. Res. Lett., 33, L20804, doi:10.1029/2006GL027287, 2006. 